\title{
The Spanish Airport-System: Lessons of Efficiency and Sustainability
}

\author{
Ane Elixabete Ripoll-Zarraga \\ Department of Accounting, London School of Economics and Political Science, London, UK
}

Copyright $@ 2015$ Horizon Research Publishing All rights reserved.

\begin{abstract}
This paper focuses on comparing the efficiency of the Spanish airports for four years (2009 to 2012). The Spanish airports are government owned and managed (AENA) under an airport-system network where non-profitable airports are cross-subsidized by profitable airports. The main discussion is if the decision-making process based on the centralisation of management may influence the efficiency of airports (technical efficiency). Furthermore, a financial analysis is performed to compare which airports although being not profitable from an accounting perspective may be using their current resources (infrastructure) efficiently. Since airports achieving profits cross-subsidized the ones that achieve negative gross margin, it could be discussed that airports with negative gross margins when technically efficient could obtain better financial results if competition is allowed. The methodology to calculate the technical efficiency level of the Spanish airports is based on non-parametric models DEA (Data Envelopment Analysis). The results show that the improvements among the years in the gross margin of the larger airports (such Barcelona and Madrid) are not a fair and true reflection their current operational performance, but a result of a centralised making-decision process (centralised management) among investments; depreciation and air fares. The results also show that airports increase significantly their technical efficiency when competing with similar-size airports, being the medium airports the ones that experience a higher increase of efficiency.
\end{abstract}

Keywords Airport-System, Competition, Data Envelopment Analysis, AENA, Regulation

There is increasing competition among airports at a regional, national and worldwide basis. Airports are increasingly seeking ways to attract airline customers, including financial packages and marketing schemes. Some airlines are well places to exploit and airport's needs to avoid traffic losses, thus giving airlines a significant edge in negotiations with airports (ICAO, Worldwide Air Transport Conference. Montreal $18^{\text {th }}-22$ th of March 2013)

\section{Introduction}

A social concern which ownership-management model should be used in the airport sector has increased considerably in recent years. Historically, the airport industry has been with others, such utilities, monopolies owned by governments (natural monopolies). In the Spanish case the pressure of local governments, professional bodies and social networks is focused unsuccessfully on obtaining the management of the airports located in their geographical areas. The government's intention to change the AENA model had an initial step on the $25^{\text {th }}$ March 2009 with the announcement of the creation of a subsidiary named initially EGAESA Empresa de Gestion de Aeropuertos del Estado, which it would be in charge of managing the Spanish Airports. Although it seemed an initial positive reform process for privatisation since private investors could participate of the equity of EGAESA, as well as followed by the creation of commercial companies where local councils and bodies could also hold shares, this process would have no impact in focusing on the main needs of the different airports: this is clustering the management for large, medium and small airports. Therefore it becomes an apparently decentralised structure with a little appeal for achieving genuine private sector participation 1 . The decentralisation of the airport network with the allowance of private management will increase the efficiency in line with the changes applied in other OECD countries with similar size airport network and political structure (Nombela, G. [87]) The airport management is decentralised in most wealthy European countries such as France, Italy, Germany and the UK, as well as overseas (Canada and the States). Although in some big cities with a high frequency of commuters and air travellers airports may have a unique management form (public sector or private sector), this is focused on defending the competition in the airport market (London, Paris, Roma and Milan). Again this was a topic publicly discussed by the Spanish Government on January 2010 under the name of 'singular airports' which included the term of 'big and complex airports' (Madrid and Barcelona). The idea was to create subsidiaries in order to manage the big airports

1 The first draft of Egaesa Statute stated that the main aim is "the management and use of the air spaces and airport services are competence of AENA, as well as the construction of future infrastructures and the way to finance them, use and maintenance' related to a 47 airports. A second draft stated that 'AENA will be able to manage and use other type of airport infrastructures' refering to handling or concessions of non-aeronautical services as shops, restaurants, etc. 
separately of the rest $100 \%$ government owned, but with the chance of including in the General Board local governments and commercial bodies (Cambra de Comerc de Barcelona [88]). The decentralisation allows specialisation (long distance, low cost, etc.) but above all flexibility when it is required a specific response to the current needs of the geographical area where the airport is located: for instance remote areas that require a minimum of routes to be provided by airlines (in regulated airports these routes are obligatory to avoid emigration or collateral negative effects to watch health and wealth of the region)

In order to understand the effects of the centralisation of management as well as ownership in the airport industry, the main question for the discussion is essentially if the AENA model airport-system has an impact in the way that airports perform, develop the operational activity (namely traffic)

In countries with remote areas, it seems to be sensible to maintain not-profitable airports to assure connectivity. Furthermore, the Governments of these countries subsidise the public services obligation routes (PSOs), these are public grants to airlines to provide the public transport between remote cities. These PSOs are common in Norway in order to keep regional remote areas connected: this is not only based on a geographical aspect, but also due to not having alternative travel modals (connectivity). Nevertheless this is not the case of Spain where passengers have other travel modalities such as high-speed train and motorways.

In the Spanish market the competition is in practice non-existent because airports do not have any managerial power to make decisions among the variables which allow market orientation: passenger choice; service provided and price. Competition starts with rivalry in the industry (Porter, M. [73]). Markets will become more competitive to the extent that they have lower barriers to entry: this is allowing airports to have managerial power to negotiate with airlines prices and quality of services. Airlines would have flexibility to operate in different airports and to compete with other airlines in prices, routes or service provided. Airports-systems ensure no-profitable airports to be subsidized by the airports that achieve positive margins. It could be discussed that negative margins are normally related to the inexistence of airlines willing to attend the current demand (if any) except for obligated remote routes where the regulator (normally the Government) ensures at least one airline operating in the airport with a minimum of transport services. Competition between airlines becomes then a utopia unless airports have more managerial power to negotiate for instance with airlines. Spanish airports that are geographically located in clashed regions could compete if the necessary conditions for competition exist (the Spanish National Board for Markets and Competition, CNMC [89]). For example, airports located in the north-west (Galicia); the north-centre and in the south (Andalucía) could compete by improving cost-efficiency; specialization as well as applying commercial policies to attract airlines.

Nevertheless, the existence of competition seems to depend on managerial decisions. A standardized system with centralization of decisions is not the best scenario to enhance competition because there is not flexibility given to the airports' management to perform commercial policies. Furthermore, a rigid making-decision process could lead to over-investments in airports as it has happened in the Spanish Airport-System.

Based on the current needs of the Spanish market, the expansion of small airports' was not required and consequently, this has been translated into an over-capacity (idle resources) for most of the airports. Furthermore, wrong (excessive) investment decisions implies public external debt with the consequent impact of financial expenses accrued in the individual airports' income statement waiving positive operational results. With this regard it is necessary to evaluate if non-profitable airports could become more profitable by reducing the existent capacity, this is to reduce the infrastructure not used potentially implying less depreciation and interest expenses to be accrued.

The capacity of airports becomes then an idle resource. Investments decisions should be carefully made. If an airport has the adequate infrastructure for its current demand, it seems that there is no need to increase its capacity unless significant increases in demand are expected for the coming years. But, is possible forecasting demand when commercial decisions (as well as others) are centralised? Investments decisions should also be made on the basis of demographic characteristics of the city-region where the airport is located (competitors; public transport; temperature; season area; etc.). It could be discussed that wrong investment decisions can lead to airports not to use fully their current capacity (infrastructure) and therefore with an over-capacity for the amount of activity performed (namely traffic). Airports are technically inefficient if they do not maximize their operational activity, if they do not produce enough aeronautical operations feasible by their current infrastructure. Smaller airports could be in this sense more efficient than larger ones.

The impact of the annual depreciation due to over-investments' decisions based on no-transparent forecast expansions, not only makes airports not to be technically efficient (idle resources), but to achieve an excessive negative gross margin. One example of over-investment (wrong forecast) is the Plan Malaga with a new terminal open in 2010, but with the same average of passengers before having the new terminal. Instead, the expansion of capacity has significantly increased the annual expense per depreciation. The overcapacity makes Malaga airport to reduce its efficiency from a significant score of $82 \%$ in 2009 before the expansion to progressively decrease it until 55\%

Additionally centralised aggressive policies regarding depreciation without being in accordance to matching convention, may lead to higher expenses when comparing airports. The charge per depreciation should be a reflection of how businesses use their assets. This is how airports use their infrastructure to perform their main activity. Based on the matching accounting convention, it should be a correlation between the income generated and the use of 
resources needed to obtain these revenues. The current regulatory framework (IFRSs; IASs and ISAs) 2 highlights that the depreciation should be a fair and true view of how companies are using their non-current assets in their main activity, and therefore the useful life of an asset should be a reflection of the expected revenues to be generated. Aggressive policies regarding depreciation lead to higher costs (consumption in monetary terms) and consequently a reduction in the operational gross margin. Since airports are not able to increase their aeronautical revenues at the same rhythm that investments are made, not only the depreciation accrued makes most of airports to achieve negative profit (losses), but does not reflect a true and fair view of their technical efficiency. During the last years non-aeronautical revenues have increased significantly compared to aeronautical revenues in Europe (Bush \& Storey [16]). In $2011,69 \%$ of the total income of the European airports was coming from non-aeronautical activities, but is this the main activity of an airport? Or could it be a consequence of lack of flexibility regarding management decisions? The economic-efficiency of airports refers the effectiveness of airports in obtaining income to cover their actual costs. The operational costs are normally disclosed in personnel; utilities; and outsourced activities (cargo; checking etc.). The infrastructure costs are normally the charge per depreciation and financial expenses incurred due to external financing resources (loans). Airports with high initial cost of investments will incur in higher depreciation charges and consequently having a higher break-even point. Airports are in need to seek alternatives to obtain revenues, even if these are not related to aeronautical operations.

The fact that depreciation decisions are also centralised and decided for all the Spanish airports as a whole, seem not to reflect the reality regarding how the airports individually use their infrastructure (capacity) in their aeronautical activity. If a percentage per depreciation is too high, the airport will have to achieve higher level of aeronautical revenues (measured for instance in flights per period) to be able to cover not only the costs of depreciation (use of terminals; runways; bridges; etc. in the same period) but, the rest of fixed costs. The way of how a specific airport consumes its assets to develop its main activity should dictate the charge per depreciation (expense for the airport) to be accrued in each period. Therefore, it cannot be possible to use the same percentages across all the Spanish airports3. In order to reflect a true and fair view of the efficiency of the Spanish System, larger airports should have higher percentage of depreciation for the same asset compared to medium or small airports. Furthermore, a fair useful life for the assets will become an effective investment forecast variable: if the percentage of depreciation chosen is correlated to how revenues are generated, capacity decisions will be in accordance with the actual airports' operational

2 IFRSs-International Financial Reporting Standards; IASs-International Accounting Standards; ISAs-International Standards in Auditing. Standards use in Europe for harmonisation proposes from 2008.

3 In example, airports with higher frequency of flights within a period of time will be using more infrastructure per year compared to airports with lower number of flights. activity.

The fact that AENA is entitled to act on behalf of the Government to change air fares suggests the discussion regarding the transparency of the process and if the Spanish Airport-System enhances an airport competitive market. The increments are to the extent of $+2,767 \%$ for Madrid Airport or $+2,116 \%$ for Barcelona from 2010 to 2011 (ACETA). The increase of fares which are going to be charged to airlines becomes a temporary solution that makes-up the reality of the Spanish airports from both technical and economic perspectives. The significant improvements in the respective gross margins are the result of increments in their aeronautical fares rather than attracting more passengers or airlines to operate. Again, if the financial statements do not reflect the reality of the Spanish airports, it is not clear if the Airport-System or the centralisation of decisions is the most effective way to respond the actual needs of the society-market.

Overall, it seems to be a correlation between unjustified significant increases in the airports' aeronautical revenues and over-investment decisions in infrastructure (such as Plan Malaga and Plan Barcelona). Nevertheless, the increase in airports' income should correspond to how airports develop their main activity (technical efficiency) and not due to discriminatory regulatory policies of changes in air fares to be charged to airlines. With this regard, it is highlighted the need of independent regulators 4 to supervise the fares that airports will impose to airlines. It is necessary to question if the changes in the aeronautical fares allow airports to become competitive, to attract airlines and therefore potential future passengers in accordance with their actual capacity (fair-efficient) and also, to ensure that these fees reflect the reality of the Spanish Airport industry.

The regulation board for the airport and railway industries (Comite de Regulacion Ferroviaria y Aeroportuaria, CRFA)[90] highlights the fact that some airport activities may be not required to be supervised though (September, 2013). These are the ones considered as rendering public services but excluding the income obtained through airports' fees 5 (such as petrol and assistance services in land) as well as commercial and aeronautical activities not subjected to price regulation. Examples of aeronautical activities with private prices are checking services or renting of surfaces within terminals by airlines (customer services). Commercial activities would include restaurants; retailer shops or car renting companies. It is important to notice that the Spanish Airport-System uses the full recovery method and consequently, the change in prices (fees) is based on the expected income to be earned by an airport equal to the expected costs to be incurred. Any subsequent event after the

4 Such as the Civil Aviation Authority-CAA in the UK.

5 The CRFA is entitled to supervise the income obtained through airports' fees. The rendering public services which are considered an income obtained through airports' fees are defined in the regulatory framework $21 / 200368.2$ a) and i) The airports' fees are the income obtained from activities that are related to the main activity of the airports such as use of runways and services provided to the use of them as well as the assistance to aircrafts; passengers and cargo; forecasting; security (passengers and cargo); use of terminals by passengers; assistance services for passengers for mobility; fingers and bridges; parking; taxi; cargo services and aerodrome traffic service. 
fee is approved for a specific period of time will imply a positive or negative impact in the financial result of each airport (income statement). The full recovery method is built on a basis that the required income per year (regulated income) should cover the operating costs as well as other costs not directly related to the main activity. This calculation allows determining the increase in fees to be charged at the following period. Considering the depreciation of assets if the percentage of deprecation is too high based on how the aeronautical revenues are earned, it could be discussed that the expected increment on airports' fees for the following period would not be reflecting the reality of the airports' business. In consequence, airports would be charging higher fees compared to what is actually required, ending in an unfair final price discriminatory compared to other European airports' businesses. Again, the financial statements should be reflecting a fair and true view of the businesses.

As it has seen, the way that airports use their infrastructure to generate their main activity will also affect the airports' technical efficiency. The financial statements should reflect the fair and true view of companies: aggressive policies regarding depreciation; aeronautical revenues not correlated to the current traffic, but based on discriminatory increases of air fares to airlines, etc. enhances the discussion regarding if the Spanish Airport-System is reflecting the reality of how the airports are performing their main activity.

Since each airport has different needs of investment based on current demand (or expected) and also based on the level of the current aeronautical activity achieved (this is how infrastructure-assets is used), each airport should be treated as a specific and different decision making unit. Airport privatisation, commercialisation and other issues such as airport infrastructure, market regulation and growth of traffic determine a dynamic and constantly changing environment. Benchmarking has become an important performance management tool in order to improve the operational performance learning from other enterprises (Francis et. al [31])

The report from the Board for competition (CNMC [89]) concludes that Spanish airports have the resources to compete (for instance in clashed zones) if management is transferred to them in order to negotiate with airlines. The centralization of the management in the Government leaves a sector with an over-investment in infrastructures not needed for the current demand and a financial debt that needs to be redeemed. The standardization of decisions ends in a low flexibility for the airports to decide essential commercial policies. The CNMC report advises the individual management per airports rather than centralisation of the decisions in order to respond to the current needs of the market: airlines; passengers or the option of other travel alternatives.

As it has seen, there is a need to demonstrate if the Spanish Airport-System allows the Spanish airports to become technically efficient and to explain the reasons of inefficiency. Furthermore, if the Spanish airports are not only inefficient, but they do not achieve positive gross margins due to the low level of activity (traffic), why should these airports be cross-subsidized by the airports that obtain positive results? Airports that are technical efficient but no-profitable, could obtain positive results if they could negotiate with airlines directly and commercial policies were more flexible. The fact that Spain does not have remote geographical areas implies that there is not a social need to maintain no-profitable airports (such it is the case of Norway). Additionally, the existent alternatives travelling modes (train; coach; car) within a reasonable distance from the airports enhances the debate regarding why is necessary to have an Airport-System (airports cross-subsidized).

Section 2 shows a revision of the literature related to different ownership and management forms as well as governance reforms in the airport industry. In section 3 an overview of non-parametric methods based on lineal programming Data Envelopment Analysis (DEA) is presented, the specific DEA-model used as well as the variables (inputs and outputs) in order to calculate the relatively technical efficiency scores for the Spanish airports from 2009 to 2012 both inclusive. The benchmarking is performed to the airports previously clustered in three groups depending on the average number of passengers. The idea is to compare each airport within its group, to determine which airports are the most efficient when performing the aeronautical activity based on using their feasible resources and therefore, the efficiency is from a technical perspective rather than economical. Since DEA benchmarks efficiency levels of making decision units within a specific period, it is necessary to analyse more than one period to ensure accuracy and reliability of the results. Section 4 summarizes the main results and section 5 includes conclusions and further research.

\section{Literature Review: Is Competition Allowed in the Spanish Airport-System?}

Since the deregulation process in Europe started in the middle of 80's (1986-87) European countries have achieved different degree levels of deregulation translated into mixed types of ownership and management. Strong evidence through the literature shows that airports with government majority ownership are less efficient than those with a private majority therefore the main question to be answered it is if the way that airports are owned and managed affects their technical efficiency. The deregulated model of ownership by excellence is the case of the British major airports (Gatwick, Heathrow and Stansted) which have improved their technical efficiency after privatization in 1987. The British example has inspired other countries to start the deregulation process in the airport industry.

Nevertheless, most of the policy debate regarding the efficacy of the airport governance reform is merely focused on the efficiency and airport charges effects of privatisation. The way that privatisation is in practise is sensitive to the nature of ownership and property rights, as well as other institutional factors which vary across frontiers (Carney et al. [18]). Scenarios with an institutional infrastructure less 
developed, therefore with not well defined property rights, without transparent regulation or liquid capital markets may make privatisation to be less effective. Privatisation is in general a term used to define different administrative structures to achieve specific objectives, but this does not describe how airport governance reform achieves these objectives.

Airports used to be considered as natural monopolies. Deregulation and liberalization of the air transport industry allows airports to compete with each other for both airlines and passengers and as a consequence, the airport market becomes more competitive and dynamic (CNMC, 89). In the Spanish Airport-System competition practically does not exist. Even airports located within the same catchment areas (approximately one hour distance driving) operate with different airlines or with the same airlines covering different routes in distance and schedules. There are a significant number of small airports (called regional) which have become public investments not used. Instead, these airports have seen increased the public financial liabilities and have recognised significant financial expenses in their individual financial statements. The impact in the financial reporting is a consequence of both investment (usually over-capacity) and forecasting wrong decisions.

AENA, the government owned and managed company that owns and controls all the Spanish airports as a whole, has also legal power to decide the air taxes that airports will be charging to airlines. Deregulation is considered as a form of privatisation that normally involves tax incentives, nevertheless since the regulator is the Government (through AENA), it seems that the process is unrealistic without any role to play. Gormley (38) highlights that deregulation also improves efficiency and economic benefits through competition. It could be discussed that if the regulator was independent to the Government, the accounting results as well as the technical efficiency of airports could improve.

Further aspects to consider when privatising (or in the Spanish case deregulating) are both public (social) and private aims. Although privatisation encourages competition it is necessary to control that private activities meet the public goals of the specific sector deregulated. It is important to be aware that tax incentives are not subsidies to the private sector and therefore, they cannot be used as the main reason to privatise. In the case of the Spanish Airport-System, partial deregulation could transfer the management to the airports individually: this is, to decentralise the decision making process currently provided by AENA.

The deregulation process in the airport sector has a vast literature since traditionally airports have been fully owned by governments and therefore treated as a public utility. Deregulation should increase competition, but empirical evidence after deregulation in Europe has been limited. Following the successful example in the UK under Margaret Thatcher's legislation other countries have privatised, partially or totally, their airports. Nevertheless, it is necessary to analyse and compare each situation (privatisation and deregulation) in order to satisfy not only the private aims such maximise the value of the company, but also the social benefits involved when regulation take place like health and safety. To deregulate the Spanish Airport-System is a utopia. Regulation becomes a constraint: all decisions are standardized and centralised for all the airports and therefore, they may be not in accordance with the real needs of the citizens or economical needs of the regions.

Again, the discussion regarding privatising some of the Spanish airports seems not to be possible since privatisation involves transferring the ownership from government owned industries to private enterprises. The privatisation of an industry is appropriate if markets work perfectly well and competition can generate efficiency (14). Furthermore, privatisation does not affect the strength of the market, except in the case of airports located closely with similar traffic profiles (47). In the Spanish airport industry, although there are a significant number of airports close to each other, the centralised management avoids airports negotiating with airlines to increase the number of services and therefore attracting passengers. Although airports seem to compete due to geographical proximity, they merely have not enough airlines, routes and passengers to use efficiently their actual infrastructure which ends in an idle resource (over-investment). Consequently, these regional airports achieve losses on an annual basis that must be subsided by the airports which are more profitable (normally big airports such as Barcelona and Madrid)

Regarding airport infrastructures, it could be possible to privatise economic characteristics to promote development, lack of competition externalities and natural monopoly practises (45)6. Again, due to the standardization of the decision-making-process centralised by AENA, it is unlikely that the Government would be willing to sell certain airports' assets to regional authorities. Furthermore, it is essential to have an adequate framework to manage the relationship between the airport operator and the government. The Government could deny privatising (or even after privatisation the industry could be regulated), if it is perceived that airport operators may exploit their market power to earn monopoly profits or having a negative environmental and social impact. From the Spanish regional authorities it has been a constant claim to request the transfer of the individual management to the airports, again the Government has been reluctant to do so; consequently it is unlikely that the airports' assets will be finally sold to the Spanish regional councils.

The review of the literature shows a concern regarding the need of privatisation in the airport industry and if regulation promotes or discourages competition. The need to liberalise the airport sector affects not only management and ownerships forms, but airline control too. The justification relays on the lack of investment as well as the impact in the operating result. The main question for the discussion is if the current investment is enough to assist the growing air traffic which affects most of the European airports. Gillen

6 There are different forms of carrying out privatisation process such as selling government owned assets, contracting out some activities (handling, fuelling, catering, etc.), deregulation and vouchers regarding some services provided by the Government; funding part of population under certain conditions, such as low incomes, disability, etc. 
(40) claims the need of reconsidering the role of governments as suppliers of investment when an expansion of capacity is needed. The aim of privatisation is the result of the inability of governments to supply the infrastructures needed and the lack of capital (41). Nevertheless, in the Spanish Airport-System the Government has over-invested in airports infrastructure (expansion of current capacities) without even having enough airlines to make the existent capacity efficient. Consequently, the Spanish airport industry not only has too much capacity for the current operational activity, but also for the expected demand forecasts. In 2013, 49\% of the Spanish airports achieved a positive EBIDTA7. After deducting the depreciation, only $31 \%$ of the airports had a positive operational result; these are 15 airports out of 49 currently existent in the Spanish Airport-System. Again, due to the over-investments made in infrastructure and the use of external resources to finance them, the financial expenses accrued implied that only 13 airports would finally achieve a positive result before taxes. This means that $73 \%$ of the Spanish airports are not profitable: these airports do not have enough number of passengers per year (airlines) in order to cover their operating costs. The airports that are profitable are located in touristic zones (Barcelona achieves the maximum profit in 2013 followed by Palma de Mallorca; Tenerife South; Gran Canaria; Alicante; Lanzarote; Ibiza; Sevilla; Bilbao and Fuerteventura); there is one hub (Madrid) and airports used as connectors to other airports or cities and therefore, potentially affected by a season effect (Girona; Valencia). The airport-system structure implies that these latest airports are subsidizing the rest of airports that do not achieve positive margins and potentially are not used efficiently. Malaga is one of the airports experimenting on the negative implications of expansions not needed (over-capacity): Malaga airport shows significant positive EBIDTAs across the years, nevertheless due to the depreciation along with the financial expenses incurred to finance the investment made in capacity becomes a no profitable airport from 2010 . Consequently, Malaga must be subsidised by profitable airports such as Barcelona, Madrid and Palma de Mallorca.

Again, the International Civil Aviation Organization (ICAO) warns about the future investments needed of at least 250 billion dollars for ten years (45). But, this is on the basis assuming airports competing with each other. In fact the ICAO states that airports must compete for both passengers and airlines: airports have had to become more commercially focused although they are still seen as monopoly infrastructure providers. Is this possible due to the Spanish Airport Industry scenario? The management is fully centralised in AENA regarding not only air fares to charge to airlines and airports investments which seem to be wrongly forecasted (or not in accordance with the expected future demand), but even regarding the useful life of the assets. Overall standardized decision making processes imply inefficiency from an operational perspective and ineffectiveness: there is not-flexibility regarding short-term decisions which are required to be made and resolved as

7 Earnings before interest, depreciation, taxes and amortisation. quick as possible in order to become competitive. Policy makers and regulators must realise about the extent of the changes that have taken place during the last twenty years with the progressive liberalization of aviation markets worldwide resulting a more competitive and dynamic market (91) In order to ensure the economic viability such infrastructure, different processes have been taken across Europe from local or federal government ownership to airport commercialization through contracts or full privatisation (4) Jensen and Meckling (49) consider ownership forms as part of the production function since they limit the feasible production of companies by deciding among technology and resources 8 . If the ownership form affects the production level, it will also influence the company's efficiency when the resources are limited or the production is capped. Privatisation improves efficiency technically and economically, but especially allows governments to provide the necessary investment that airports cannot achieve: government investments in infrastructures are required in order to end recessions and to increase the current productivity (25)9. Again, it seems that the Spanish airports are rewarded by over-investments (technology), but instead they are not economical efficient (accounting perspective). Oum, Adler and $\mathrm{Yu}$ (61) demonstrate that the reason behind commercialisation and privatisation processes is the access to financial resources, investment as well as the improvement of operational efficiency. Their results demonstrate that airports with government majority are considerably less efficient than airports with private majority, although partial privatisation seems not to improve the operating efficiency. Pestana and Dieke (68) also prove that fully private managed airports have higher efficiency compared to partially privatised. The allowance of private presence in the airport industry is the result of decentralisation of decisions, but also efficiency decisions by increasing competition (45). White (83) defines 'privatisation' from five different points of view; one definition is the process based on contracting-out certain activities in order to improve the current efficiency or to reduce inefficiency by retaining public control. Therefore, it is possible to achieve certain levels of efficiency without being fully privatised. The Spanish Airport-System responds to a fully centralised control: airports government owned and managed, managed as a whole and based on standardization of decisions. Airports as mature firms should be able to survive by their own, they should cover the operating costs by generating enough income, but since airports are considered as public goods governments cap the level of investment and provide the needed capitals. Nevertheless airports have to compete with other areas of public expenditure such as health and education in order to receive the adequate financial resources (32) Oum (61) pleads for a sensible view to consider airports owned by governments

8 The relationship between ownership forms and performance of companies is located in the Agency Theory which does not agree with the Managerial Theory in the sense that different ownership structures does not imply same size-return combinations.

9 Costas-Centivany (1999) identifies the infrastructure needs in the Spanish airports as a consequence of the growth of the tourism. 
less efficient than being owned by private companies in the same conditions. The reasonable explanation is that when the owner is the government, the objectives are not clearly defined and also they change in every legatorial period $(8,27$, 51). Although the Spanish Government (AENA) has provided excessive investments in capital, most of airports are not profitable due to over-investments translated into excessive depreciation charges and financial expenses accrued into the financial statements. The break-even point has been pushed forwarded to a level of traffic that it seems impossible to achieve due to the characteristics of the Spanish market: firstly airports do not compete because they do not have enough airlines operating and different airports cover different routes, but secondly there are alternative modals of travelling such as motorways and railways. Additionally, the Spanish airports' management not only does not enhance competition, but ensures transferring financial resources from profitable airports to airports with losses. Based on the literature findings and due to the specific characteristics of the Spanish Airport-System, it is essential to demonstrate firstly if this System is efficient from a technical perspective rather than economical (accounting).

Humphries (47) defends private participation since it is an efficient and cost effective way for the government to maximise revenue and at the same time to improve customer and quality services. The main reason to privatise Australian airports and other type of business owned by governments is the reduction of government debt without raising taxes (46). Under private ownership, the increase of revenues is due to the deviation of resources to airport activities able to provide cash-flow: activities that they do not have impact in the revenues do not receive investments. The idea is to incentive those areas that maximise the performance of the airport such as departure and arrival areas 10. It is inadequate that AENA being a government owned company is not subsidised, but especially because of having managerial independence to exploit the individual earnings of airports (25). An open market is the efficient way for the government to maximise revenues without losing customer services and quality (32). Different ownership forms regardless of fully ownership government or private increase cost efficiency (62). Empirical evidence comparing the performance before and after privatisation concludes that private ownership in competitive markets represents the conditions for improving the current performance. The fact of having a mixed ownership model may provide a chance to achieve the best of both public and private sectors: private ownership model does not necessarily improve the company performance (8)

Despite the interest in analysing the effects of different management and ownership forms in airports' performance, it is not cleared which combination is more effective. The relation between ownership and performance cannot be assessed on its own, it is necessary to take into consideration policy concerns (8). The government regulatory policy has implications in financial performance after beginning the

10 BAA has invested resources only in those activities that contribute to generate income in Heathrow Airport (Pope, 1996). privatisation process. There are additional difficulties when assessing the relationship between ownership and performance since privatisation enhances revenues (ICAO states in their report [91] that commercial revenues are as important overall as aeronautical revenues), whereas the government could be more focused on providing financial resources or decisions based on increasing social welfare. The International Civil Aviation Organisation (ICAO) recommends avoiding regulation of airports in areas where competition is already effective in order to avoid detriment of customers (91)

Starkie (75) points out that competition is good for the economy as it pushes companies to be cost efficient: to drive down prices leading to expanding levels of output. Market imperfections are not a sufficient justification for government regulation. If regulation takes place in a sector the process should be analysed periodically. Airports costs are predominantly fixed due to the investment in infrastructure (through the annual depreciation of the non-current assets), but also due to operational costs related to safety and security which do not reduce even if the airport traffic increases (scale economies). Consequently airports have huge incentives to reduce costs by diversifying the main aeronautical activity towards a commercial revenues (e.g. car parking). The profitability of airports depend on the traffic volume, as aeronautical revenues increase depending on the number of passengers whereas the costs increase slower due to the fixed component of the depreciation of the infrastructure. Therefore, airports must compete to retain and attract traffic (new airlines) (91). Nevertheless in the Spanish Airport-System the centralisation of the management along with the standardization of decision processes, avoids opportunities for the airports' individual management negotiating and attracting airlines. Airports managed independently achieve higher levels of market orientation, resulting in higher commercial and aeronautical revenues as well as lower costs. In the case of an airport-system, this is more than one airport managed by the same company, the financial trade-offs for an airport include the possibility of receiving professional managerial advise as well as cross-subsidies. Regulated airports may cause prices no competitive and therefore to appear less efficient comparing to airports managed under no-regulated market conditions (4) In the Spanish case the fact of not allowing airports to manage their own revenues to finance their operating costs, ends up in no profitable airports being subsidized by the airports which maximise their operational performance. This is also facilitated due to AENA is self-financed exclusively with aeronautical and commercial incomes. Indeed, cross subsides may not encourage cost minimisation since the losses of less economic efficient airports are financed by the more profitable ones. As it has been seen, in the Spanish market where not competition exists; airports do not have their own individual management in order to facilitate the flexibility in the decision making process and airports are cross-subsidized, there are no incentives to maximise profits. There is no place for economic efficiency.

Gerber (35) analyses the ideal market conditions for privatisation to be successful. The main reasons behind 
privatisation are the unused potential of the government owned airports that should be used, but more important the natural monopoly of terminals and runways that remain after privatisation has been concluded 11 . If the natural monopoly is misused, conflicts may appear regarding the main objectives between the owners and the society. The danger of a monopoly misused tends to appear because of the interest of the owners to earn higher results and in a fast way. As a consequence, privatisation becomes a process against the interest of airlines and customers. Furthermore privatisation may then cause less quality and safety instead of an increase of efficiency because investment has not been carried out.

Gillen and Llall (41) point out that the conditions with airports must survive are not competitive at all due to the constraints such as regulatory, political or even social and geographical. These authors link the airport conditions with the customer satisfaction as well. They consider that variables such as runways and terminal capacity must be taken into consideration in order to attend the peak demands and avoid potential delays. They state that the rhythm of the economy affects straight on to airport efficiency because all factors are exogenous and therefore the inputs cannot be changed yearly 12. The Air Transportation Association (ATA) estimated the value of inefficiency in the air traffic cost to the airlines companies more than 3 billion of dollars in 1995 (48) Sarkis (74) considers that airline companies choose airports depending on their efficiency level tending to select those that are more efficient. Nevertheless, this should be accompanied by an effective decision making process in accordance with individual management rather than centralisation of decisions.

It is not evidenced which is the effective way to assess the airports' performance when fully government owned and managed. Performance could be understood from a pure financial accounting perspective (operational result, gross margin, or result for the period in the income statement) or from a managerial point of view as the way that airports perform their ordinary course of business. Since AENA does not publish disaggregated annual reports the analysis of performance can only be done from a managerial perspective: evaluating each specific airport by comparing the aeronautical activity achieved in relation with the airport's current resources (namely infrastructure) and benchmarking its technical efficiency level to the rest of the airports. This seems to have a conflict with literature with authors considering that regulation does not facilitate efficiency analysis. The process to privatise and commercialise airports is the main factor to assess the efficiency of airports. The absence of airport competition with geographical, political and regulatory restrictions, do not allow measures to measure the efficiency of airports (58) Since airports are different regarding the services offered, in a competitive environment the market will equal profitability and the

11 The cash flows generated by natural monopolies come from aeronautical revenues (departures) and other taxes as well as from non-aeronautical revenues (Koll and Stevins, 1999)

12 Any industrial private company that experiments a reduction of revenues in a specific period can improve its cash-flow by adjusting the production level. Governement owned and/or managed companies are subject to restictions that may be focused in social benefits instead. optimal performance for each airport 13 Nevertheless Gormley (38) states that theories regarding to which one is preferred government or market, should be tested. It is necessary to take into consideration both premises: firstly that privatisation process is a multidisciplinary discipline and secondly a study of privatisation process needs to be analysed in a comparative analysis (benchmarking). The first statement defends evaluating privatisation in different policy areas, levels of government (e.g. regional councils or departments) and countries. The second premise is referred to compare forms of governance across or within frontiers.

The revision of literature shows that most studies take into consideration the terms of 'competition' and 'competitive environment' as well as the relation between ownership and management forms and their potential effects in airports' performance. Privatisation increases competition, but it seems to generate a potential conflict of interests between government and private owner-operators and also a bias from aeronautical activities to commercials in order to finance the operating costs of running the airport. Authors agree that governments cannot provide the necessary investment to supply enough airport activity for congested airports (high volume of traffic). Evidence through literature shows that fully government (or private) forms do not necessary will imply better economic and social results. Privatisation or commercialisation reforms follow to increase both financial performance and operating efficiency, but much deeper is the consequence of the lack of capital when airports are government owned.

Again, there is not enough evidence to prove which ownership and management model is more effective to reduce the interests' conflict between the government and the market. Also which model or combination has a better impact in airports' performance: empirical evidence may show that private ownership is more adequate to improve the company performance, nevertheless it is essential to have a competitive market. It has been evidenced that the Spanish Airport-System is not the best model to enhance competition. The fact that airports are managed as a whole and that decisions are highly-centralised ends in a standardized process not appropriate to respond to the rapidly environmental changes. Additionally, most of the Spanish airports are no-profitable (economic efficiency) and the profitable airports must subsidise airports with significant accumulated losses. Consequently, it is necessary to evaluate if fully government owned and managed (operated) is adequate to generate competitive conditions of the market, and therefore to supply a good service for customers, as well as a positive potential contribution in airports' performance. This study is based on analysing the impact of the Spanish Airport-System from the operational efficiency perspective: this is, to critically assess which airports are the most technically efficient due to their current infrastructure. Due to the investments' decisions made by the Spanish

13 Profitability is defined as the relationship between the result obtained and the investment required in a period. In presence of competition, therefore privatisation, investments made by airports will be fully covered and therefore the ratio will be higher than the unity. If the ratio is smaller companies achieve losses equal to (1-ratio) $\%$ 
Government in the latest years, it could be discussed that airports which have experimented excessive expansions without a proportional increase of their demand (traffic) will become technically inefficient and by extension, the expansion managerial decisions would have been wrongly made. The efficiency analysis is based on a benchmarking meaning that the efficiency level of a specific airport is estimated based on the airport's current technology (infrastructure), but at the same time by comparing the airport's actual operational performance to the rest of airports. The airport operating activity is defined in terms of output measured through the annual number of passengers, cargo and air traffic movements.

\section{Methodology}

Efficiency is referred to the relation (ratio) between inputs and outputs when one of these variables is pre-determined or exogenously restricted. This definition is based on the assumption that companies have limited resources or inputs such as technology, infrastructure, etc. and therefore, the production frontier has a boundary (feasible output surface). Efficiency has two possible interpretations from an economic and technological point of view. Economic efficiency is referred to the use of combinations of feasible resources in order to obtain the lowest production cost per unit of output possible. Technological efficiency is the relation between the maximum amount of output subject to a limited amount of resources, or the minimum amount of resources used to produce a determined level of production.

In this paper the technological efficiency concept is evaluated since the unknown purchasing costs of the inputs are relatively difficult to estimate. Technological efficiency is related to the current resources that an airport uses to develop its main operational activity and therefore, it represents purely how airports perform. Technical efficiency measure also allows a more accurate benchmarking due to be focused on the number of resources used instead of their value, where the cost of inputs could be distorting the reality when comparing two different airports (e.g. an airport with low production cost may be using a high number of resources than another one but at better price. This implies economic efficiency but not to be technical efficient). Economic efficiency is mainly based on inputs prices which are external variables: they are rarely changeable as they are fixed by the suppliers and not by companies. Activities such as material purchases, outsourcing activities and staffing levels are directly influenced by the airport management (4); in the Spanish scenario these decisions are not made by airports but by AENA (exogenously restricted).

In the airport sector a harmonised definition of technological efficiency is complicated due to the divergences between airports regarding the availability of resources. In this sense the amount of resources that an airport requires to develop its ordinary course of business may be different depending on the airports' environment existent in each period (customer demand, regulatory restrictions, season, etc.). Resources are normally related to infrastructure which goes beyond the airports size (large, medium or small surface). The infrastructure or potential capacity to be used is defined through different components of the airport's structure such as number of runways, terminal buildings, boarding gates, and checking desks, terminal size, parking capacity, permanent employees, etc. The airport operational activity is seeing as the main output of airports although there is not a shared definition. The literature shows a common use of aeronautical activities such as aircraft movements, passenger traffic and cargo but also non-aeronautical since additional revenues from commercial business have been shown to contribute to higher efficiency scores (59) Hooper (46) quotes that using 'revenues' as a measure of output could become a problem when airports have some kind of monopoly power. This author also recalls that it is required to demonstrate if non-aeronautical revenues how some kind of influence in the productivity ratio of airports infrastructures.

The overall technical efficiency score can be disaggregated into two sources of efficiency: pure technical efficiency and scale efficiency. This separation is possible because the technical efficiency depends on the type of returns to scale, variables or constant. Returns to scale refers to increasing or decreasing efficiency based on size (2). Constant returns to scale (CRS) means that the producers are able to linearly scale the inputs (input orientation) or outputs (output orientation) without increasing or decreasing efficiency and therefore any variation of resources or production level do not improve the current efficiency level14. The technical efficiency under the assumption of constant returns to scale (CRS) is the overall measure which is used to determine the main causes of inefficiency based on the relation of quantity of inputs and outputs (pure technical efficiency) and also due to the size of operations (scale efficiency). Variable returns to scale (VRS) assume proportional variations of inputs (decreases) or outputs (increases) to improve the level of efficiency achieved in a specific period. Therefore by modifying the amount of resources the output will increase more than proportional compared to the amount of inputs used and consequently, the efficiency level will also change. The pure technical efficiency is obtained under variable returns to scale and reflects the impact of managerial decisions in the production process among the quantity of resources to be used or the level of production to be achieved. Therefore it can be used as measure of the managerial performance within the company. The ratio between the overall technical efficiency and the pure technical efficiency is the scale efficiency.

The scale efficiency is the ability of managers to choose the optimum size (amount of resources within the feasible surface) to obtain the pre-determined production level (or to choose the maximum production level achievable based on the current resources available). In Figure 1 the pre-determined production level is the point A (YA) which based on the current technology requires a specific minimum amount of resources (XA). If instead the airport is using

14 If the inputs, for instance number of runways and terminal buildings, increase by a factor of 2 , the airport activity will also be double, and therefore the efficiency score will remain the same than in the previous period. 
more inputs $(\mathrm{XB})$ than the amount required for the expected output (YB = YA), then it becomes scale inefficient under decreasing returns to scale (DRS): airports can achieve the same amount of activity (namely traffic) by using a lower number of resources.

Point $\mathrm{C}$ is the case of airports which are not achieving the expected production (YA) since they are not using enough resources $(\mathrm{XC}<\mathrm{XA})$. These airports are scale inefficient under increasing returns to scale (IRS), since an increase of inputs (XA - XC) will achieve the production target (YA). For instance, airports with only one runway or low staffing level will probably have difficulties to get a large number of flights per day compared to others with two runways or more employees.

Generalising increasing returns to scale (IRS) is related to companies using a small size of inputs for the level of operations pre-determined (output) and therefore in order to become scale efficient, they will have to increase the current number of resources; decreasing returns to scale (DRS) is referred to a large size of inputs for the amount of operations performed since with lower quantity of resources it is possible to achieve the same production level.

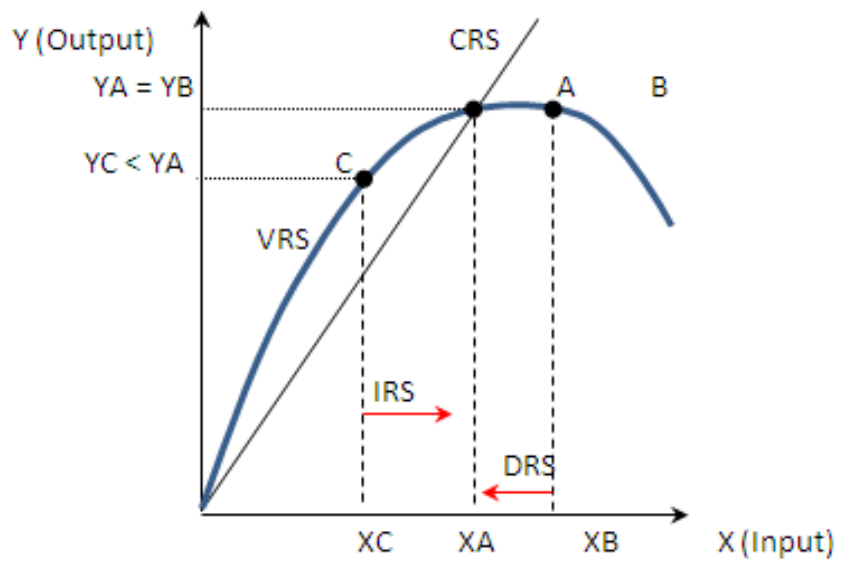

Figure 1. Returns to scale in the production process

The most productive scale size (MPSS) is the best size given the current input combinations. Due to the size of operations this is the level of production pre-determined, the company achieves this target by using the most efficient combinations of all the inputs required in the production process. Consequently, it is not required any variation in the current amount used, reducing (DRS) or increasing (IRS) because the company is scale efficient (A). In the airport industry, the amount of production expected can be related to the number of take-offs/landings per day. The MPSS will be that combination of number of runways, terminal buildings, checking desks, baggage belts, employees, etc. needed to achieve the target. If an airport has too much capacity (for instance too much employees, terminal buildings, checking desks not used, etc.) it will become scale inefficient, because with less number of employees and infrastructure, it is possible to achieve the same amount expected of flights per day. Over or under-capacity takes place when the size (amount of resources used) is not the adequate to the activity produced: a small airport can be more scale efficient than a big one because the last one is not using all its feasible resources to develop the expected airport activity 15 .

\subsection{Data Envelopment Analysis (DEA)}

The aim of benchmarking is to search outside of the enterprise in order to achieve the best practice in the production process to gain competitive advantages. Holloway (44) defines 'benchmarking' as the process where the company enhances its current performance by learning from successful practises of its competitors. It is a partnership cooperation process and a mutual benefit over a period of time. Camp (17) defines it as a positive and proactive process changing operations in order to obtain a higher performance. Therefore, benchmarked best practice becomes the best process by comparing similar activities to produce a specific operational activity. This definition shows the insight that benchmarking goes beyond performance measures because it concerns learning and practise process (31).

There are several methodologies to calculate efficiency which are generally classified as parametric and non-parametric. Parametric functions are pre-defined before analysing the characteristics of the observations and therefore they assume an established relation between dependent and independent variables. Non-parametric functions are not based in a predicted function form, this means that the relation between variables is not assumed, but will depend on the specific database used. The production function is the result of the association between variables based on the information across the observations. In this research a non-parametric model of Data Envelopment Analysis (DEA) is used. Airports are different from each other due to having different level of resources available and therefore it is not possible to define the same production function for all the Spanish airports.

DEA has been applied in multiple airport researches over the last 15 years. Data Envelopment Analysis (DEA), originally developed by Charnes et al. (20) and subsequently extended by Banker et al. (13), is a non-parametric linear programming-based method to evaluate the relative efficiency of a set of homogeneous decision making units (DMUs). In DEA there are two fundamental approaches: radial and non-radial. Both approaches are related to projections 'path to follow' by the inefficiency units in order to achieve the competitive frontier, to become efficient. The radial projections introduced by Debreu (28) and Farrell (30) are based on the proportional reduction in inputs (or increase in outputs) in order to improve the efficiency of the units analysed. Non-radial projections were introduced by Koopmans (50) and Russell (73). Charnes et al. (21) was the first author proposing an additive model, non-oriented DEA, to estimate efficiency scores based on a proportional reduction (increase) of inputs (outputs) and additional slacks variables in order to achieve the frontier. The disadvantages of this model rely on efficiency scores ranging between 0

15 For example considering the case of Barcelona airport after the new terminal is finished, the DEA scores may show scale inefficiency under decreasing returns to scale. Returns scale analysis provides further arguments regarding the effectiveness of managerial decisions. 
(inefficient) and infinite, and also the slacks not always assure the shortest way to become efficient. As a result modifications of this model have been done in order to improve the initial weaknesses (slack measures 15, 24; 79. Distance functions 5, 29). Nevertheless, non-radial models which incorporate slacks variables into a single efficiency measure have not been that commonly used. The majority of studies of airport benchmarking using Data Envelopment Analysis have been based on radial models: constant returns to scale (12) and variable returns to scale. Some other studies use both type of returns in order to estimate technical and scale efficiency levels in the airports operations $(6,54)$

The literature in the airport sector shows the interest of researches in using DEA models to evaluate the way that airports compete within the airport industry by using different variables across countries. The Spanish case has been considered in a reduce number of studies, probably due to the difficulties to access to disaggregate data per airports. Also the studies have been based on one period (normally one year) rather than more. This becomes a limitation since by evaluating one year it is not possible to provide enough evidence to explain the plausible reasons behind the competitive frontier (if a second methodology is used) but above all because of the competitive frontier results are no reliable due to a lack of dynamism: DEA provides a snap shot of the efficiency level of the units in an specific moment of time, but not variations between periods 16 .

In DEA the technical efficiency can be calculated based on two managerial decisions among inputs and outputs. Input orientation models are focused on a proportional reduction of the amount of resources used to produce the specific determined production. Output orientation will involve decisions of increasing the current level of production to achieve the competitive frontier. The efficiency score for each decision making unit $\bar{i}$ and for each period $(\theta \bar{i} t)$ is calculated as a relation between the optimum amount of resources (minimum possible quantity of inputs) and the current quantity used if the model is input orientated. If it is output orientated then the efficiency level is the relation between the current production levels and the possible to be achieved based on the feasible inputs (maximum outputs)

$$
\begin{aligned}
& \theta \overline{\mathrm{t}} \text { (input orientation) }=\frac{\text { Min Inputs } t}{\text { Actual Inputs } t} \\
& \theta \overline{\mathrm{l}} \mathrm{t}\left(\text { output orientation) }=\frac{\text { Actual Outputs } t}{\text { Max Outputs } t}\right.
\end{aligned}
$$

The overall technical efficiency score represents the divergence between the actual production and the feasible production (see Figure 2). A unit is technically inefficient overall if the current production is located under the boundary of the production set determined by the competitive frontier under constant return to scale (CRS).

16 This can be compared to the financial statements of a company such as balance sheet or income statement. They do not provide a reliable base to make decisions. An external consultant will have to seek further information in order to determine which causes have brought the company to that situation, and that involves reviewing annual reports, evaluation of the internal and accounting control systems, external auditor's report, etc.
The scale efficiency is obtained by comparing the technical efficiency under the assumptions of constant returns to scale (CRS) and variable returns to scale (VRS). The pure technical efficiency level is measure as the distance to the variable returns frontier. Pure technical inefficiencies are due to managerial bad performance in making decisions whereas the overall measure is due to both managerial performance and size of operations; as it has been seen before if these are large, then the unit is scale inefficient under decreasing returns to scale (DRS); if the operations are too small, then the unit is scale-inefficient under increasing returns to scale (IRS)

Figure 2 shows that the constant return to scale frontier (CRS) is achieved only by one decision making unit(DMU1). The units 1,2,3 and 5 are efficient under variable returns to scale assumption (VRS). Projecting the inefficient DMU4 to the VRS frontier to minimize the quantity of inputs used holding the pre-determined production level (input orientation), the unit becomes $100 \%$ pure technical $\operatorname{efficient}\left(\theta \overline{\mathrm{i}} \mathrm{t}=\mathrm{X}_{4}^{\prime} / \mathrm{X}_{4}\right)$.

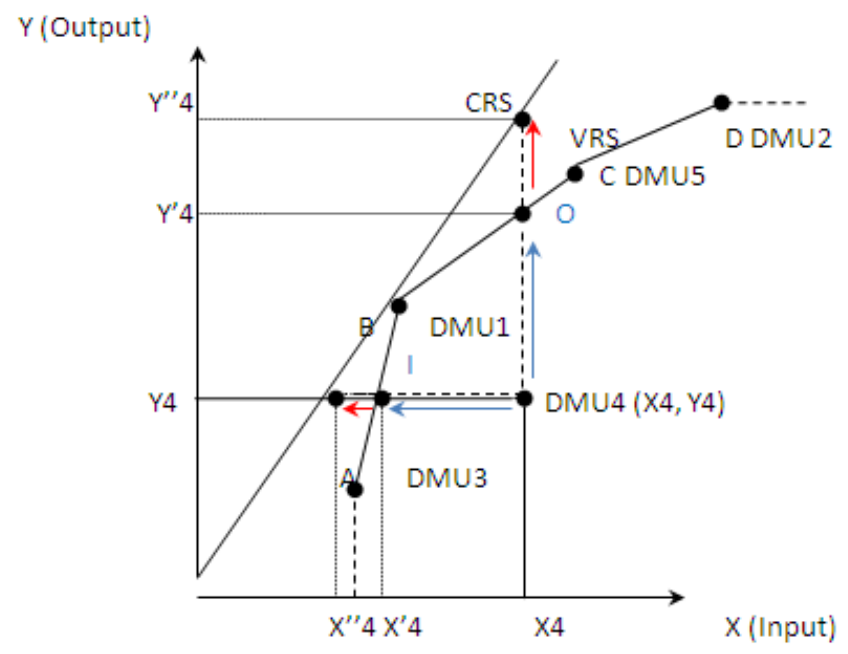

Figure 2. Competitive frontiers: projections of inefficient units

If the model is output orientated, the projection is based on variating the level of output and holding the amount of resources, in this case the projection is toward the VRS frontier $(\mathrm{O})$ which makes the unit pure technical efficient $\left(\theta \overline{\mathrm{i}}=\mathrm{Y}_{4} / \mathrm{Y}_{4}^{\prime}\right)$. The overall technical efficiency is focused on the CRS frontier: by projecting the actual amount of resources used the unit becomes efficient $\left(\theta \overline{\mathrm{i}} \mathrm{t}=\mathrm{X}^{\prime \prime}{ }_{4} / \mathrm{X}_{4}\right)$. Again if the model is output orientated the overall technical efficiency is defined as the ratio between the actual production obtained using a pre-determined inputs $\left(\mathrm{Y}_{4}\right)$ and the maximum production feasible $\left(\theta \overline{\mathrm{i}} \mathrm{t}=\mathrm{Y}_{4} / \mathrm{Y}^{\prime \prime}{ }_{4}\right)$. When a unit is efficient its score is equal to the unit and therefore it is posible to establish the equivalence $X^{\prime \prime}{ }_{4} / \mathrm{X}_{4}=\mathrm{Y}_{4} / \mathrm{Y}^{\prime \prime}{ }_{4}$ which assures that the type of orientation does not change the level of efficiency achieved by a decision making unit. In the same way the scale efficiency scores are equal to $\mathrm{X}^{\prime \prime}{ }_{4} / \mathrm{X}^{\prime}{ }_{4}$ if the model is input orientated and $\mathrm{Y}_{4}^{\prime} / \mathrm{Y}^{\prime \prime}{ }_{4}$ if it is output orientated.

The estimation of how well a company performs can be achieved through several methods. The main reason applying Data Envelopment Analysis (DEA) is due to its advantages compared to other techniques. DEA is 
non-parametric linear programming method to calculate the relative efficiency of decision making units (DMUs). A decision making unit can be any unit involved in transforming inputs (resources) into outputs (products-services). The units are assessed on a basis of a productivity ratio defined as the relation between the sums of the outputs and the sums of inputs without describing a specific form of the production function. DEA methodology is considered in the group of non-parametric techniques. Parametric methods are based on stochastic cost and production functions, which a specific distribution, defined prior to the research. Non-parametric methods include partial and total factor productivity indexes as well as DEA. Partial factor productivity indexes (labour, capital, etc.) do not consider differences in cost of the inputs and also the aggregation of inputs and outputs is unable because they may be measured in different units. Total factor productivity indexes allow the aggregation, but require costs information and further research if the results will be used in management strategies and making decision processes. DEA does not require price information: variables can be measured in currency or physical units without any need to disaggregate them. Therefore, this methodology is really useful in sectors where prices and costs are unknown or the outputs are difficult to define such as hospitals, councils, banks, governments, etc. Furthermore, DEA allows the aggregation of multiple inputs and outputs compared to partial productivity indexes and different feasible combinations of inputs-outputs. DEA draws the relation between outputs and inputs as an efficiency production surface which can be achieved with the current technology or management strategy applied by the company (41). One of its disadvantages is that it is very sensitive towards potential outliers and provides unreliable results when the number of inputs and outputs are much larger compared to the observations (58). Outliers are identified through a super-efficiency analysis; by removing the outliers from the initial sample the rest of observations increase potentially their initial efficiency levels.

The BCC model is based on the CCR radial model (20)17. The BCC model features variables returns to scale (VRS) which are more flexible and reflect managerial efficiency apart from purely technical limits (82). Variable returns to scale assumes the relation between dependent and independent variables non-proportional: producers cannot linearly scale inputs and outputs without increasing or decreasing efficiency. Any decision of increasing or decreasing the current amount of inputs used will affect the efficiency score (3). Based on airport managers discussions

17 CCR (Charnes et al. 1978), BCC (Banker et al. 1984) which improves the Debreu-Farrell efficiency, since this ignores the presence of non-zero slack. Radial technical inefficiency means that all inputs can be simultaneously reduced by $\theta$ without altering the proportions in which they are utilized. The other type of DEA models are additive, (Charnes et al., 1985) which is based on the Pareto-Koopmans (mixed) efficiency: a decision making unit is fully efficient if and only if it is not possible to improve any input (or output) without worsening one or more of its other inputs (or outputs). An observation is rated as relatively efficient if, and only if, there are no output shortfalls or resource wastage at the optimal solution. Due to the units' invariance properties, a normalized, weighted, additive DEA (Lovell and Pastor (1995)) may be used in place of the simple additive. and literature review, the variable returns to scale model seems to be more appropriate to measure airport efficiency (4) The variable returns to scale provides economies of scale, which is important since small airports tend to have increasing return to scale. They also allow including variables with negative or zero value that are essential, for instance when airports have no cargo (53)

BCC model can be applied from two alternatives of orientation (ditto CCR). The orientation is referred to variables relatively easy to be changed by the management in the short term, variables that are not exogenously determine also called discretionary. In the input orientation version, the production resources are modified whereas in the output model changes in the production amount will be made in order to improve the efficiency level achieved by a decision making unit. Input orientated DEA models quantify the input reduction that is necessary to be made to become technically efficient by holding the production constant. An output orientated DEA model will quantify the expansion of production necessary to become technically efficient with a fixed amount of inputs. A non-orientated measure quantifies improvements when both inputs and outputs can be changed simultaneously. In the airport sector inputs seem to be modified relatively easier compared to airports' output. In the Spanish market the level of airport activity (output) seems to depend more on external factors such as demand of flights and other variables related to management decisions (attraction of airlines, price, etc.) that they are centralised decisions made by AENA. The input orientation in DEA assumes that the main output, namely airport traffic, is exogenous and therefore it cannot be changed or impacted by the airport management or in other words it is given. The input-orientated model is focused on minimising the amount of resources used in the ordinary course of business to achieve a target of output level. Consequently, inputs including runways and terminals are assumed being semi-variable (not fixed) and therefore relative easier to be changed regarding the amount to be used when updating the airport activity to the current demand. The output-orientated model is referred to maximise the output and therefore inputs are considered to be fixed in the short run, or exogenously restricted. Both versions imply that only discretionary variables, not restricted, affect the efficient targets for inefficient units. In this case decisions among inputs are made by inefficient airports to achieve the frontier, to become efficient, but decisions to change the number of passengers, cargo or air traffic movement are not viable. An airport can improve its current technical efficiency by changing the way that it is using its resources, less amount of inputs, but not by increasing the number of passengers per year.

The Banker's model (9) in its input orientation version assumes that the efficiency score $(\theta \overline{\mathrm{l}})$ for each decision making unit unit $\overline{\mathbf{l}}(D M U \overline{\mathrm{l}})$ is determined by the way that the current resources are used in order to achieve a fixed (expected) production level of airport activity. The BBC model in its input orientation version for a specific decision making unit ì (DMŪi) follows,

$$
D \overline{\mathrm{i}} t(X j \overline{\mathrm{I}} t, Y i \overline{\mathrm{I}} t)=\operatorname{Min} \theta \overline{\mathrm{l}}
$$




$$
\begin{gathered}
\text { s.t. } \sum_{\overline{\mathrm{i}}^{\prime}=1}^{\leq k} Y i \overline{\mathrm{l}}^{\prime} t \cdot \lambda \overline{\mathrm{l}}^{\prime} \geq Y i \overline{\mathrm{l}} t \\
\sum_{\overline{\mathrm{i}}^{\prime}=1}^{\leq k} X j \overline{\mathrm{l}}^{\prime} t \cdot \lambda \overline{\mathrm{l}}^{\prime} \leq \theta \overline{\mathrm{l}} \cdot X j \overline{\mathrm{l}} t \\
\sum_{\overline{\mathrm{i}}^{\prime}=1}^{\leq k} \lambda \overline{\mathrm{l}}^{\prime}=1 \\
\lambda \overline{\mathrm{l}}^{\prime} \geq 0
\end{gathered}
$$

The objective function is the minimization of the distance of a specific decision making unit to the efficiency frontier where are located the units who are the most efficient. The DEA models are based on the current technology existing in a period $t$ describing the conjunct of internal processes within the production process: consequently, DEA does not imply dynamism but a snap shot of the current competitive frontier in a specific moment of time. Investments made from one period to the next one are known as technological change which represents the potential increase of the current production capacity. This can be quantified by the Malmquist Index which also quantifies variations in efficiency due to investments in new technologies. In this paper the fact of analysing more than one period responds to the need of providing dynamism to the DEA frontier. Changes in technology are understood as investments in the current infrastructure which will be incorporate in the value of the non-current assets across the years. Each $D M U \bar{i}$ uses $m$ resources $(X j, j=1, \ldots m)$ in producing a pre-determined level of production represented by $n$ outputs $(Y i, i=1, \ldots n)$. In each period the objective function minimise the distance between the airport and the frontier formed by the best airports (technically efficient). The solution to the linear program $D \overline{\mathrm{l}} t(X j \overline{\mathrm{l}} t, Y i \overline{\mathrm{i}} t)=\theta \overline{\mathrm{l}}$, is the technical efficiency level representing the way that a specific airport $\overline{1}$ performs; this is how it is using its feasible resources to produce a fixed airport activity $(Y i \bar{i})$. The efficiency score obtained from the optimisation model represents the distance of the decision making unit to the competitive frontier: if $D \overline{1} t(X j \overline{1} t, Y i \overline{1} t)=1$, then the unit is allocated in the frontier and therefore technically efficient. If the efficiency score is lower than the unity $D \overline{1} t(X j \overline{1} t, Y i \overline{1} t)<1$ the distance to the frontier $(1-\theta \overline{\mathbf{l}})$ measures its technical inefficiency. Since the efficiency score is calculated from the feasible current resources, the frontier is potentially achievable by any inefficient unit: the inefficiency or distance to the competitive frontier can be reduced with its current technology. The reference group of an inefficient unit are similar units, but are best practitioners. The peers become the guidance of the inefficient $D M U^{1}$ to improve its performance, to reduce the amount of resources used. The restriction of lambdas is referred to the reference group built by $k$ units $\left(\overline{\mathrm{l}}^{\prime}=1 \ldots k\right)$. Each competitor $\overline{\mathrm{i}}^{\prime}$ has some relative influence when making the airport analysed technically inefficient: the importance is measured with relative weights represented by the lambdas as percentages $\left(\lambda \bar{i}^{\prime} \geq 0\right)$ being the total sum equals to the unity $\left(\sum_{\bar{i}^{\prime}=1}^{\leq k} \lambda \vec{i}^{\prime}=\right.$ 1). The main competitors become the reference to the airport evaluated to use the resources in a better way. If there is only one main competitor the restriction of sum of lambdas will be equal to the unity, a similar situation to a monopolistic power.

The other two restrictions bound the production volume and consume of inputs. The first restriction states that the production level of an airport $(Y i \bar{i})$ cannot be higher than its references. The second restriction determines that the amount of resources used by the unit is higher or equal to its competitors $\left(\sum_{\overline{\mathrm{I}}^{\prime}=1}^{\leq \boldsymbol{k}} X j \overline{\mathrm{i}}^{\prime} t \cdot \lambda \overline{\mathrm{i}}^{\prime}\right)$. The potential improvement of efficiency is calculated by the proportional reduction of the current amount of resources used $(\theta \overline{\mathbf{l}} \cdot X j \overline{1} t)$

Following Adler et al. $(1,2)$ principal components analysis (PCA) is applied in order to avoid redundancy of the variables used. The main idea of using PCA within DEA context (PCA-DEA) is to increase the discriminatory power of the model of Banker. Frequently when using DEA an extensive number of decisions making units result efficient because of the excessive number of inputs and outputs used to do the benchmarking (1). PCA-DEA version allows optimising the number of variables to use in DEA without losing the information contained in any of the original ones. By reducing the initial number of inputs and outputs, the number of efficient units is lower than when applying the traditional DEA which retains $100 \%$ of the information contained in the variables. The procedure is based on quantifying how much information of the efficiency score is explained for each input and output. The inputs and outputs that individually do not explain enough of the efficiency level of each airport are removed from the original sample and include in the other inputs and outputs which influence more the efficiency score. 


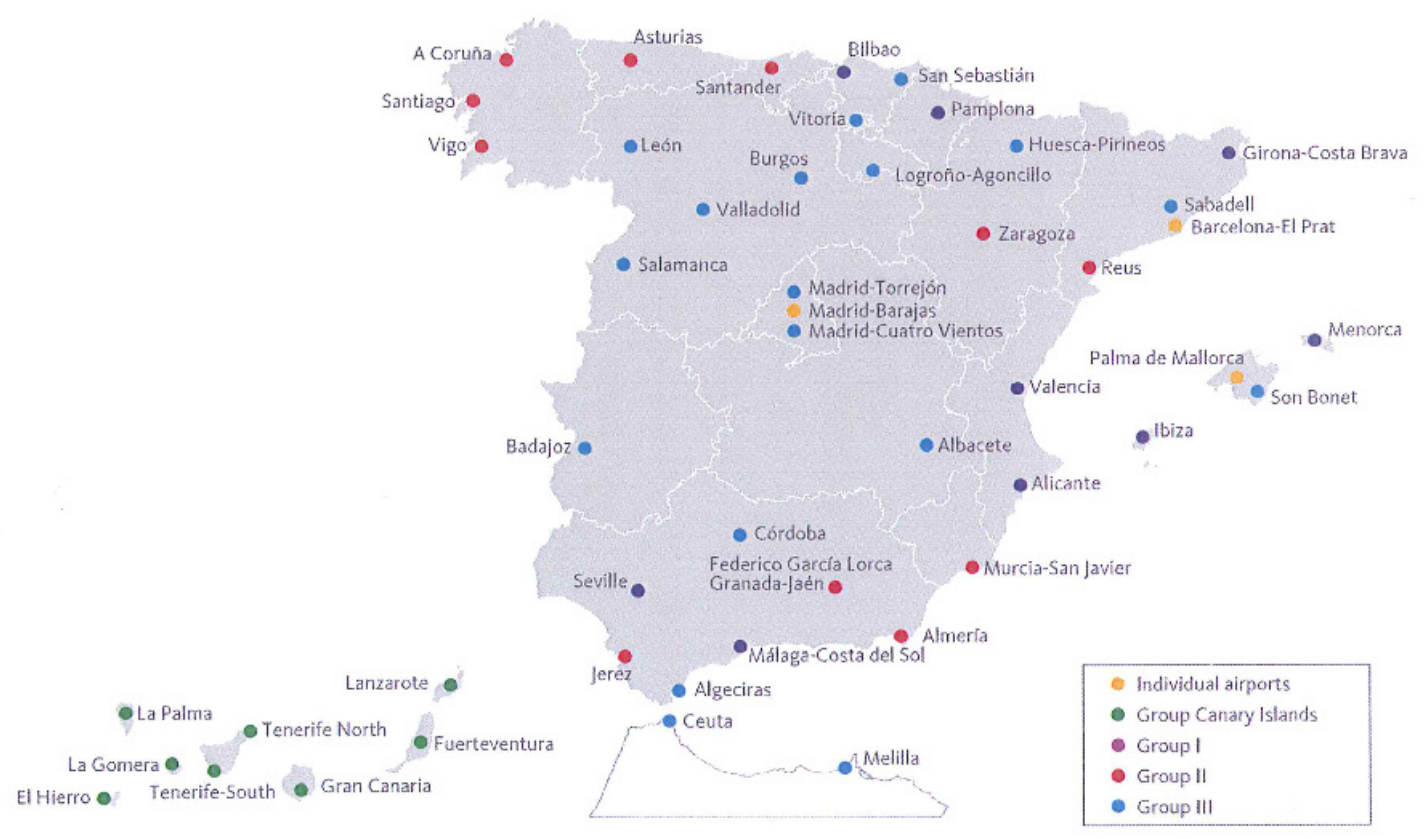

Figure 3. Spanish airport network (Source: AENA Annual Report, 2011)

\subsection{Data Description}

In order to measure the efficiency of the Spanish airports, it is necessary to identify the main resources used in the operational airport activity. Since privatisation has not occurred in the Spanish airport market and evidence through literature proves the bias toward commercial activities, it would be sensible to define the ordinary course of business from the aeronautical perspective (rendering of public services- prestaciones patrimoniales publicas, 90). Non-aeronautical revenues are the only discretionary output over which the influence of management can be substantial (4) Non-discretionary variables are externally determined and therefore they are beyond the control of management in the short run or exogenously restricted (9). Nevertheless since the airports' management is centralised by AENA, and therefore the Spanish airports do not have decision power among their current situation, but instead solidarity decisions are made across all the airports as a whole, it is necessary to take into consideration the fact that some airports may have an important contribution from commercial activities to the total income earned in the Spanish airport industry (especially in small airports with less frequency of flights per year when the aeronautical income could be nil in some months). Consequently, the main focus of this analysis is the operational activity of the airports based on those inputs that mainly contribute to the gross margin of the airports. The gross margin is the result of the difference between revenues (aeronautical and commercial activities) and the costs incurred to earn them.

An overall concept which summarizes the aeronautical inputs used in the airport industry is the airports infrastructure. Nevertheless the review of literature shows that the capital variable (infrastructure) is difficult to define or quantify. One of the main challenges of airport benchmarking analysis is the inclusion of capital measures (63). Different measures of a proxy of capital have been used in airport industry research: Parker (63) estimates rent expenses; Murillo and Melchor (57) depreciation and Barros and Sampaio (11) use the book value of the tangible assets (this is its current cost deducted by the accumulated depreciation). In other studies a proxy-measure is based on the airport's physical inputs such runways, gates, parking spaces, terminal and airport area $(41,74,64)$. Adler (4) states that these measures can be problematic if comparing regulatory frameworks across countries, but it is possible to avoid the influence of differences in estimation if the historical cost is obtained by using the disclosures of the annual reports. The harmonisation of the accounting standards (International Accounting Standards-IASs) has been applied in Spain from January 2008 where the introduction of concepts such as net realisable value, reducing balance method, value in use, recoverable amount, fair value, revaluation model, impairment of assets, etc. were used for the very first time. Generally speaking the amortisation tables tended to be publicly published by governments allowing companies to use the same percentage of depreciation before 2008. With the new international standards, the amortisation per year is a more accurate measure since it should be a reflection of the number of years that companies are going to use the fixed asset to generate revenues (accruals and matching accounting conventions). As stated the percentages of depreciation applied to the financial statements of the Spanish airports is based on a centralised decision made by AENA. Discussions with airports' managers have highlighted that AENA uses (dictates) very aggressive percentages of depreciation, and therefore these seem not to be related to the reality of the Spanish airports business model. Each airport should be analysed independently from the others because each airport has a relatively significant different number of flights per year, number and type of airlines operating, current and potential passengers, etc. and consequently by considering this output, the percentage of depreciation could be 
accurately established. The usage of the airport infrastructure (consumption of assets reflected through the annual depreciation) as well as other inputs used to generate the airport main activity are different in each airport: centralised depreciation decisions of the airports' assets could be the reason of being technically inefficient. If the individual management is transferred to the airports, decisions regarding changing the actual depreciation percentages in order to be closer to the specific airport's business model could improve its technical efficiency.

In this study three inputs and five outputs have been used to estimate the efficiency level of the Spanish airports from 2009 to 2012. In the input side, staff cost (wages); charge per depreciation (reflecting the consumption or use of infrastructure) and other operating costs incurred by the airports. In the output side the number of passengers per year; the air traffic movements and the goods transported including all types of traffic and goods such as in transit as well as aeronautical and commercial revenues. The employees' cost does not include the services provided in terms of air traffic control (ATC). It has not been possible to differ between permanent and fixed employees, as well as full or part time. It could be discussed that permanent employees may have higher impact in the efficiency scores compared to part-time. Again, it has not been possible to distinguish different job categories. Airports would incur in different costs depending on the different tasks related to positions. The fact of analysing more than one year compared to other studies prior done in the AENA case, allows the introduction of dynamism and therefore, consistency and reliability in order to draw accurate conclusions based on the results obtained.

All the inputs that are measured in monetary units (currency) have been adjusted using the purchasing power parity (PPP) specific for each year. The PPP conversion factor comparing to the U.S. dollar is the number of units of a specific country's currency required to buy the same amount of goods and services in the domestic market (as U.S. dollars would buy in the United States and therefore the PPP for U.S. is equal to one). By using the PPP the effect of changes in prices (inflation or deflation) across years is eradicated allowing comparing data across the four years. Also, the efficiency scores are estimated reliably since they are not affected by the inflation rate that could reflect higher nominal costs compared to the real ones. The main idea is to obtain the efficiency scores for each year and to compare the consistency of the efficiency frontier through time. The use of real data (instead of nominal) allows comparisons in different periods. Since DEA is a non-dynamic non-parametric tool the scores reflect a snapshot of the current situation for the period analyse, but not the variations between periods. Therefore it is necessary to analyse more than one year in order to achieve accurate results and conclusions of the current situation of the airports managed and owned by AENA.

A good rule-of-thumb when applying DEA is to include a minimum set of data points in the evaluation to discriminate better between efficient and inefficient units. Cooper (2001) states the number of decision making units (airports) should be at least three times bigger than the inputs and outputs used With a proper number of observations the surface in each period is constructed smoothly, avoiding instability in the value of efficiency scores from period to period: the units that are technical efficient in one period remain efficient across different years providing and accurate efficient frontier to be evaluated in the second stage. In this study, a final sample of 48 airports with data related to three outputs and five inputs is reliably enough to build the competitive frontier. The heliport of Algeciras has not been included since it started its activity in 2010 and therefore in 2009 all the variables would become missing. DEA cannot perform for decision making units containing all variables equal to zero. Getafe has also been removed from the database since it is an army air base as well as other civilian airports which no data has been obtained. Finally airports used for private flights and flight academies have been also included in the sample with the idea of comparing differences in efficiency with other type of airports.

An initial correlation analysis has been made in order to detect the association between inputs and outputs. The idea is to detect potential predictors with perfect relation between them (collinearity) since this leads to a model being overall significant, but containing explanatory variables which are not individually statistically significant. The correlation matrix that includes all the inputs and outputs shows high correlation between all variables $(>0.70)$. This may imply a potential problem of collinearity, since there is a perfect linear relation among the variables. Nevertheless these correlations seem to be sensible; one would expect to have similar variability between the number of passenger, cargo and movements: if the number of passengers increases then cargo and movements also would increase. Also if an airport has a high number of passengers, both the aeronautical (0.9619) and the commercial income $(0.9826)$ would be expected to be higher. Operating costs related to personnel $(0.9498)$ as well as other operating costs $(0.9701)$ could also be higher compared to other situations when the number of passengers is relatively low. The expenditure of wages will be also higher since the labour costs represent an essential input to develop the aeronautical activity. The lowest correlation is between cargo and wages $(0.7727)$ suggesting that airports may outsource this activity and therefore, although it has an impact in the other operating costs of the airports (0.9254), these are not directly related to employees' costs.

In order to test the collinearity, a regression is performed using these variables as response variables. This is each input and output is regressed as dependent variables against the others. These regressions are done individually in order to see if the rest of inputs and outputs have a specific individual impact and if it is significant. Due to having three inputs and five outputs a total of eight regressions will be performed. The values of Tolerance $\left(1-R^{2}\right)$ and the variance inflation factor (VIF) by $1 /$ Tolerance are computed for each regression. VIF values higher than 10 may need further examination since it is evidence of potential collinearity. The results for all regressions show higher values of 10 (when wages is regressed among the other inputs and outputs its VIF is 18.92 ; for depreciation the VIF is 112.61 and for other 
operating costs 325.08 In the output side the VIF for passengers is 73.54; for ATM 47.56; for cargo 16.78; for aeronautical income 52.45 and for commercial income 120.44). Further analysis need to be performed in each regression to confirm the existence of collinearity between the inputs and outputs: when collinearity exists the model tends to be significant overall, but the predictors (independent variables) are not significant. In the eight regressions performed, most of the inputs and outputs are statistically significant $(P>|t|$ is $<$ than 0.05$)$. For example in the regression of wages, the charge per depreciation $(P>|t|=0.254)$; ATM $(P>|t|=0.804)$ and cargo $(P>|t|=0.909)$ are not significant. The regression of charge per depreciation has no-significant wages $(P>|t|=0.254)$ and commercial revenues $(P>$ $|t|=0.115)$. The regression of other operating costs shows as no-significant only the constant $(P>|t|=0.648)$ being the rest of the inputs and outputs significant. In the output side, the regression of the number of passengers per year has no significant both type of revenues, aeronautical $(P>$ $|t|=0.238)$ and commercial $(P>|t|=0.104)$ as well as cargo $(P>|t|=0.055)$. ATM shows no-significant wages (0.804); cargo (0.227); and commercial income (0.299). Cargo has wages (0.909); passengers (0.055) and ATM $(0.227)$ as well as the constant (0.391). Aeronautical income has no significant, the number of passengers (0.238) and the constant (0.651). Finally the commercial revenues is not influenced by the charge per depreciation (0.115); the number of passengers per year (0.104); ATM (0.299). As it seen, there is no consistency regarding the relevance of the inputs and outputs in the different regressions. Some inputs and outputs are no significant in specific models, but in other models are significant. Overall most of the variables are significant across the eight regressions performed. Furthermore, if collinearity exists between explanatory variables (predictors), these should have similar standard errors and also similar regression coefficients. In all the regressions performed the standard errors (for no significant variables) differ from each other as well as the coefficient indicating the no presence of collinearity. There are two regressions with similar standard errors: the one of ATM with a standard error for wages of 210.1915 compared to commercial income with a standard error of 203.8466. These two standard errors could indicate collinearity, nevertheless the regression coefficients differ between them in signed and value (-52.29 indicating a negative impact of wages with the number of air traffic movements and a coefficient of +212.14 indicating a higher and positive impact of the commercial revenues). This also happens for the regression when including depreciation that shows a standard error for wages equal to 0.1145813 and for commercial revenues equal to 0.1110733 , but with different regression coefficients $(-0.13$ and +0.18 respectively). In conclusion these tests demonstrate that although the correlation between inputs and outputs is high, these relations between variables do not show the presence of collinearity and therefore, there is no need to remove them from the initial sample.

\section{Results}

The BCC model has been applied to four groups of airports: the first DEA includes all the airports together without separating between large, medium and small. The next DEAs have been applied to each group of airports clustered by the number of passengers per year. The idea is to observe the change in efficiency when competing with airports that exceed their current size to the efficiency levels achieved if competing with similar airports. The size of the airports has been defined in terms of passengers per year (MPAX). The airports are classified into the groups based on consistency of number of passengers across the four years of the study. In consequence, if one airport achieves exceptionally high demand in one year only, the criteria for clustering are the average number of passengers. The next table shows the classification group for each airport based on the average of passengers from 2009 to 2012.

Table 1. Airports classification: clusters

\begin{tabular}{|c|c|c|c|c|}
\hline Airports & Group & MPAX & Min MPAX & Max MPAX \\
\hline \multicolumn{5}{|l|}{ Alicante; Barcelona; Bilbao; Fuerteventura; Gran Canaria } \\
\hline Ibiza; Lanzarote; Madrid Barajas; Malaga; Palma de Mallorca & Big & $>3,500,000$ & $3,654,957$ & $49,866,113$ \\
\hline \multicolumn{5}{|l|}{ Sevilla; Tenerife North; Tenerife South; Valencia } \\
\hline A Coruña; Almeria; Asturias; Girona-Costa Brava & & $\leq 3,500,000$ & & \\
\hline Granada-Jaen; Jerez; La Palma; Menorca & Medium & $>750,000$ & 728,428 & $5,286,970$ \\
\hline \multicolumn{5}{|l|}{ Murcia; Reus; Santander; Santiago; Vigo } \\
\hline \multicolumn{5}{|l|}{ Albacete: Badajoz; Burgos; Ceuta; Cordoba; El Hierro } \\
\hline \multicolumn{5}{|l|}{ Huesca-Pirineos; La Gomera; Leon; Logroño; Madrid 4 vientos } \\
\hline Madrid Torrejon; Melilla; Pamplona; Sabadell; Salamanca & Small & $\leq 750,000$ & 0 & 751,097 \\
\hline San Sebastian; Son Bonet; Valladolid; Vitoria; Zaragoza & & & & \\
\hline
\end{tabular}


The first DEA when including all the airports highlights as technically efficient airports (100\%) in at least one year and with consistency high scores in the rest of the years Madrid and Palma de Mallorca18. The next table summarizes the efficiency level of the Spanish airports when analysing altogether:

Table 2. DEA-Output all airports (2009-2012)

\begin{tabular}{|c|c|c|c|c|c|c|c|c|c|c|c|}
\hline & Average & 2012 & 2011 & 2010 & 2009 & & Average & 2012 & 2011 & 2010 & 2009 \\
\hline A Coruña & $27.49 \%$ & $22.88 \%$ & $25.48 \%$ & $28.77 \%$ & $32.85 \%$ & $\begin{array}{l}\text { Madrid } \\
\text { Barajas }\end{array}$ & $96.13 \%$ & $100.00 \%$ & $100.00 \%$ & $95.96 \%$ & $88.56 \%$ \\
\hline Albacete & $72.29 \%$ & $72.23 \%$ & $74.01 \%$ & $70.48 \%$ & $72.44 \%$ & $\begin{array}{c}\text { Madrid } 4 \\
\text { vientos }\end{array}$ & $69.51 \%$ & $43.93 \%$ & $63.67 \%$ & $73.57 \%$ & $96.87 \%$ \\
\hline Alicante & $75.52 \%$ & $52.38 \%$ & $68.61 \%$ & $87.37 \%$ & $93.71 \%$ & $\begin{array}{l}\text { Madrid } \\
\text { Torrejon }\end{array}$ & $45.95 \%$ & $18.58 \%$ & $42.99 \%$ & $56.60 \%$ & $65.61 \%$ \\
\hline Almeria & $23.56 \%$ & $19.35 \%$ & $23.99 \%$ & $25.65 \%$ & $25.25 \%$ & Malaga & $63.97 \%$ & $53.50 \%$ & $60.07 \%$ & $62.50 \%$ & $79.79 \%$ \\
\hline Asturias & $28.42 \%$ & $25.41 \%$ & $26.77 \%$ & $31.68 \%$ & $29.82 \%$ & Melilla & $23.91 \%$ & $18.43 \%$ & $24.77 \%$ & $26.57 \%$ & $25.88 \%$ \\
\hline Badajoz & $79.77 \%$ & $68.26 \%$ & $71.77 \%$ & $87.33 \%$ & $91.71 \%$ & Menorca & $32.77 \%$ & $28.38 \%$ & $34.52 \%$ & $35.01 \%$ & $33.17 \%$ \\
\hline Barcelona & $85.98 \%$ & $89.71 \%$ & $90.13 \%$ & $80.18 \%$ & $83.88 \%$ & Murcia & $34.84 \%$ & $29.60 \%$ & $31.32 \%$ & $35.32 \%$ & $43.13 \%$ \\
\hline Bilbao & $67.52 \%$ & $56.51 \%$ & $70.31 \%$ & $70.38 \%$ & $72.87 \%$ & $\begin{array}{l}\text { Palma de } \\
\text { Mallorca }\end{array}$ & $96.98 \%$ & $89.81 \%$ & $98.84 \%$ & $99.28 \%$ & $100.00 \%$ \\
\hline Burgos & $59.43 \%$ & $68.93 \%$ & $58.24 \%$ & $54.06 \%$ & $56.49 \%$ & Pamplona & $23.79 \%$ & $17.50 \%$ & $22.99 \%$ & $26.60 \%$ & $28.07 \%$ \\
\hline Ceuta & $87.07 \%$ & $100.00 \%$ & $93.04 \%$ & $77.98 \%$ & $77.26 \%$ & Reus & $34.70 \%$ & $22.63 \%$ & $30.21 \%$ & $40.61 \%$ & $45.37 \%$ \\
\hline Cordoba & $48.17 \%$ & $57.83 \%$ & $45.39 \%$ & $42.66 \%$ & $46.80 \%$ & Sabadell & $75.63 \%$ & $47.13 \%$ & $71.33 \%$ & $84.03 \%$ & $100.00 \%$ \\
\hline El Hierro & $37.40 \%$ & $32.48 \%$ & $38.46 \%$ & $39.16 \%$ & $39.50 \%$ & Salamanca & $47.83 \%$ & $35.66 \%$ & $45.85 \%$ & $54.95 \%$ & $54.87 \%$ \\
\hline Fuerteventura & $57.99 \%$ & $47.56 \%$ & $62.63 \%$ & $63.68 \%$ & $58.10 \%$ & $\begin{array}{c}\text { San } \\
\text { Sebastian }\end{array}$ & $28.41 \%$ & $22.89 \%$ & $29.12 \%$ & $30.27 \%$ & $31.38 \%$ \\
\hline $\begin{array}{c}\text { Girona-Costa } \\
\text { Brava }\end{array}$ & $69.37 \%$ & $41.23 \%$ & $48.65 \%$ & $87.61 \%$ & $100.00 \%$ & Santander & $30.61 \%$ & $24.75 \%$ & $32.15 \%$ & $31.31 \%$ & $34.24 \%$ \\
\hline Gran Canaria & $88.38 \%$ & $75.82 \%$ & $91.85 \%$ & $91.42 \%$ & $94.42 \%$ & Santiago & $30.44 \%$ & $20.54 \%$ & $33.13 \%$ & $33.81 \%$ & $34.27 \%$ \\
\hline Granada-Jaen & $25.59 \%$ & $18.53 \%$ & $27.58 \%$ & $26.64 \%$ & $29.62 \%$ & Seville & $60.56 \%$ & $50.48 \%$ & $64.34 \%$ & $62.50 \%$ & $64.91 \%$ \\
\hline $\begin{array}{l}\text { Huesca- } \\
\text { Pirineos }\end{array}$ & $62.10 \%$ & $66.76 \%$ & $53.49 \%$ & $56.12 \%$ & $72.04 \%$ & Son Bonet & $86.13 \%$ & $77.11 \%$ & $100.00 \%$ & $87.95 \%$ & $79.47 \%$ \\
\hline Ibiza & $66.12 \%$ & $58.60 \%$ & $70.44 \%$ & $69.71 \%$ & $65.72 \%$ & $\begin{array}{l}\text { Tenerife } \\
\text { North }\end{array}$ & $68.93 \%$ & $51.34 \%$ & $69.89 \%$ & $75.54 \%$ & $78.96 \%$ \\
\hline Jerez & $45.28 \%$ & $34.12 \%$ & $47.96 \%$ & $43.04 \%$ & $56.00 \%$ & $\begin{array}{l}\text { Tenerife } \\
\text { South }\end{array}$ & $64.00 \%$ & $56.84 \%$ & $69.36 \%$ & $64.25 \%$ & $65.54 \%$ \\
\hline La Gomera & $51.39 \%$ & $50.55 \%$ & $53.68 \%$ & $49.05 \%$ & $52.28 \%$ & Valencia & $77.38 \%$ & $57.93 \%$ & $76.34 \%$ & $87.38 \%$ & $87.85 \%$ \\
\hline La Palma & $21.26 \%$ & $17.71 \%$ & $20.61 \%$ & $22.49 \%$ & $24.24 \%$ & Valladolid & $26.50 \%$ & $22.07 \%$ & $26.61 \%$ & $28.67 \%$ & $28.63 \%$ \\
\hline Lanzarote & $68.47 \%$ & $56.94 \%$ & $73.21 \%$ & $72.94 \%$ & $70.77 \%$ & Vigo & $23.81 \%$ & $17.94 \%$ & $20.68 \%$ & $27.36 \%$ & $29.26 \%$ \\
\hline Leon & $32.58 \%$ & $30.22 \%$ & $32.39 \%$ & $33.24 \%$ & $34.45 \%$ & Vitoria & $28.57 \%$ & $17.06 \%$ & $38.56 \%$ & $28.08 \%$ & $30.59 \%$ \\
\hline Logroño & $44.63 \%$ & $35.56 \%$ & $44.37 \%$ & $48.63 \%$ & $49.95 \%$ & Zaragoza & $82.61 \%$ & $95.47 \%$ & $87.40 \%$ & $80.91 \%$ & $66.65 \%$ \\
\hline
\end{tabular}


The next following three DEAs are applied to each group of airports. The first group are the larger airports with more than $3,500,000$ passengers per year. The results of the second frontier are summarized in the following table:

Table 3. DEA-Output Big airports (2009-2012)

\begin{tabular}{cccccc}
\hline & Average & 2012 & 2011 & 2010 & 2009 \\
\hline Palma de Mallorca & $96.52 \%$ & $87.92 \%$ & $98.97 \%$ & $99.19 \%$ & $100.00 \%$ \\
Madrid Barajas & $96.41 \%$ & $100.00 \%$ & $100.00 \%$ & $96.28 \%$ & $89.36 \%$ \\
Gran Canaria & $91.06 \%$ & $77.05 \%$ & $94.37 \%$ & $94.78 \%$ & $98.04 \%$ \\
Lanzarote & $89.80 \%$ & $72.78 \%$ & $92.43 \%$ & $96.92 \%$ & $97.07 \%$ \\
Bilbao & $89.73 \%$ & $72.00 \%$ & $92.11 \%$ & $94.81 \%$ & $100.00 \%$ \\
Tenerife North & $88.57 \%$ & $67.27 \%$ & $89.02 \%$ & $97.99 \%$ & $100.00 \%$ \\
Fuerteventura & $88.50 \%$ & $68.79 \%$ & $85.58 \%$ & $99.63 \%$ & $100.00 \%$ \\
Valencia & $88.40 \%$ & $66.61 \%$ & $87.76 \%$ & $99.23 \%$ & $100.00 \%$ \\
Barcelona & $86.35 \%$ & $88.72 \%$ & $91.08 \%$ & $81.25 \%$ & $84.36 \%$ \\
Ibiza & $82.95 \%$ & $69.86 \%$ & $85.42 \%$ & $88.80 \%$ & $87.70 \%$ \\
Alicante & $80.49 \%$ & $56.11 \%$ & $73.94 \%$ & $92.67 \%$ & $99.24 \%$ \\
Seville & $76.21 \%$ & $64.79 \%$ & $78.62 \%$ & $79.16 \%$ & $82.25 \%$ \\
Tenerife South & $69.52 \%$ & $59.97 \%$ & $74.81 \%$ & $70.92 \%$ & $72.36 \%$ \\
Malaga & $66.51 \%$ & $55.08 \%$ & $62.90 \%$ & $65.72 \%$ & $82.35 \%$ \\
\hline
\end{tabular}

All of these airports have also positive gross margins. The gross margin is an indicator of how well the companies are performing in their ordinary course of business 19 . One would expect to have the highest value of gross margin possible compared to other fixed costs not related directly to the main activity of the company. In the case of the Spanish airports, the gross margin has been calculated based on financial data of aeronautical and commercial revenues deducted from cost of employees (except the air traffic services such as control traffic); charge per depreciation as reflection of the consumption of the infrastructure and other operating costs.

Barcelona; Madrid and Palma de Mallorca are the airports with higher gross margin due to have enough revenues to cover the costs of the business (see Table 4). Barcelona and Madrid have a significant charge per depreciation (expense) accrued compared to Palma de Mallorca. These lead to a discussion if the investments made in both airports have been useful to expand (to attract more passengers). With this regard in 2012, Barcelona achieves a high and similar gross margin $(+214,43$ million of euro) compared to Madrid $(+201,79)$, showing that with less investment in physical capital it is possible to achieve similar results. In 2010 both airports had similar negative gross margin (-87,32 Barcelona; $-82,73$ Madrid), but in 2009 Madrid's result $(-121,30)$ represents three times more the losses of Barcelona $(-38,52)$. Lower number of airlines operating in the airport implies less revenues earned therefore, the usage of the infrastructure reflected as charge per depreciation becomes a fixed expense to be absorbed by other income indirectly related to the main activity such as the revenues generated by commercial activities.

19 The gross margin in financial accounting is equal to the sales earned during the year less the costs of sales. The cost of sales can be calculated based on the production cost per unit (if this is a manufacturing company) or acquisition cost per unit (if the company is commercial)
Table 4. Gross margin Big-airports with higher passengers per year

\begin{tabular}{ccccc}
\hline & 2012 & 2011 & 2010 & 2009 \\
\hline Barcelona & 214,43 & 45,12 & $-87,32$ & $-38,52$ \\
Madrid & 201,79 & 73,44 & $-82,73$ & $-121,30$ \\
Palma de & 124,32 & 77,48 & 53,15 & 53,69 \\
Mallorca & $-17,70$ & $-18,66$ & $-20,58$ & 34,01 \\
Malaga &
\end{tabular}

In 2012, the depreciation of the non-current assets of Palma de Mallorca represents the $13 \%$ of the depreciation of Madrid and the $24 \%$ of the total depreciation in Barcelona. These percentages are consistent across the years. Furthermore, Palma de Mallorca shows a positive and consistent gross margin from 2009 to 2011 (see Table 4). These results show that although an airport may have higher capacity (measured for instance through investments in infrastructure) compared to other airports 20 , does not ensure achieving higher gross margin: there is no relation between how big is an airport in terms of infrastructure and its aeronautical revenues since these depend on how well the airports uses its capacity to develop the ordinary course of business (passengers; ATM and cargo). This is confirmed by the regression of the aeronautical revenues for the biggest airport (see Table 5) showing a significant influence of the annual depreciation $(P>|t|=0.021)$, but with negative impact $(\beta j=-0.9050)$ : the higher de charge per depreciation due to bigger capacity, the lower the aeronautical revenues. This is relevant for airports that have bigger capacity (infrastructure) and is not used in the operational activity (idle resource). With this regard the airport not only become no profitable, but also technically inefficient.

20 For instance number of terminals; runways; aircraft parking; cargo warehouse; number of belts; checking counters, etc. 
Table 5. Regression Aeronautical Revenues (Big-airports)

\begin{tabular}{|c|c|c|c|c|c|c|c|c|c|}
\hline Source & & S & $d f$ & MS & & \multirow{2}{*}{\multicolumn{2}{|c|}{$\begin{array}{l}\text { Number of obs }= \\
F(7, \quad 48)=\end{array}$}} & & 56 \\
\hline & \multirow{2}{*}{\multicolumn{2}{|c|}{2151667.82}} & & & & & & \multirow{2}{*}{\multicolumn{2}{|c|}{$\begin{array}{l}362.61 \\
0.0000\end{array}$}} \\
\hline Mode 1 & & & 7 & 307381.118 & & \multicolumn{2}{|c|}{ Prob $>\mathrm{F}=$} & & \\
\hline Residual & \multicolumn{2}{|c|}{40688.6027} & 48 & 847.679223 & & \multicolumn{2}{|c|}{ R-squared } & \multicolumn{2}{|c|}{0.9814} \\
\hline Total & \multicolumn{2}{|c|}{2192356.43} & 55 & 398610259 & & \multicolumn{2}{|c|}{$\begin{array}{l}\text { Adj R-squared }= \\
\text { Root MSE }\end{array}$} & \multicolumn{2}{|c|}{$\begin{array}{l}0.9787 \\
29.115\end{array}$} \\
\hline \multicolumn{2}{|c|}{ aeronauticalincome } & \multicolumn{2}{|c|}{ Coef. } & Std. Err. & t & $P>|t|$ & {$[95 \%$} & Conf. & Interval] \\
\hline & ages & \multicolumn{2}{|c|}{2.149305} & .8200408 & 2.62 & 0.012 & \multicolumn{2}{|c|}{.5005023} & 3.798107 \\
\hline \multicolumn{2}{|c|}{ depretiationassets } & \multicolumn{2}{|c|}{-.9050921} & .3796822 & -2.38 & 0.021 & \multicolumn{2}{|c|}{-1.668494} & -.1416898 \\
\hline \multicolumn{2}{|c|}{ otheroperatingcosts } & \multicolumn{2}{|c|}{.8660637} & .6025094 & 1.44 & 0.157 & \multicolumn{2}{|c|}{-.3453627} & 2.07749 \\
\hline & $\operatorname{mpax}$ & \multicolumn{2}{|c|}{$5.07 e-06$} & $2.71 e-06$ & 1.87 & 0.067 & \multicolumn{2}{|c|}{$-3.70 e-07$} & .0000105 \\
\hline & atm & \multicolumn{2}{|c|}{-.0008197} & .0003038 & -2.70 & 0.010 & \multicolumn{2}{|c|}{-.0014304} & -.0002089 \\
\hline & $\operatorname{argo}$ & \multicolumn{2}{|c|}{$7.95 e-07$} & $1.94 \mathrm{e}-07$ & 4.10 & 0.000 & \multicolumn{2}{|c|}{$4.05 e-07$} & $1.19 e-06$ \\
\hline commercial & come & \multicolumn{2}{|c|}{1.358014} & .6076116 & 2.24 & 0.030 & \multicolumn{2}{|c|}{.1363289} & 2.579699 \\
\hline & cons & \multicolumn{2}{|c|}{-13.09979} & 12.82681 & -1.02 & 0.312 & \multicolumn{2}{|c|}{-38.88982} & 12.69024 \\
\hline
\end{tabular}

Palma de Mallorca has $80 \%$ more passengers than Malaga and five times more cargo on a constant basis, but its charge per depreciation is half of the depreciation accrued by Malaga (except for 2009). It could be discussed that Palma de Mallorca is using in an efficient way its resources (infrastructure) compared to Malaga, or that Malaga has an over-capacity for its current level of activity. Effectively the expense per depreciation of Malaga across the years is due to an expanding process started in 2005 by AENA called Plan Malaga.

The initial part of the expansion of Malaga airport was focused in building a new terminal of 251,000 metres squared with the idea of increasing the number of passengers in peak areas to 9 million and forecasting 20 million of passengers when finished. The new terminal was opened in 2010. Nevertheless from 2005 to 2012 there are not significant changes in the number of passengers per year being in average 12.6 million 21 . These findings enhance the discussion regarding if the investment plan budgeted to expand the actual capacity of Malaga airport was really needed to attend the future potential demand: either the forecast of 20 million passengers was optimistically wrongly made or the investment in Malaga airport has been excessive for the operational activity. The last alternative would be to critically discuss the effectiveness of the Spanish Government (through AENA) when managing public resources.

Furthermore, the new regulatory framework applied in Spain from January 2008 states that companies must recognise an expense per depreciation even if the assets are not use in the ordinary course of business. In consequence, any asset related to the airport infrastructure (terminals; runways; etc.) must be depreciated even if they are not used due to not having for instance airlines operating in the airport

21 Before the construction of the new terminal Malaga airport has $12,669,019$ passengers in 2005 and 12,046,277 passengers in 2004 (source AENA) (e.g. Castellon airport). If the investment in Malaga has been wrongly forecasted (this is based on the future demand expected), the higher cost of the expansion will be reflected in a higher value of depreciation per year (expense) and unless enough revenues are generated, the lower usage of the infrastructure (or idle-usage) will have a negative impact in the gross margin of the airport. In 2009 Malaga has a really low charge per depreciation (in fact Palma de Mallorca is $48 \%$ higher compared to Malaga). Additionally, the fact that the airport is not over-dimensioned, implies that Malaga uses its resources in an efficient way, this is Malaga uses most of its capacity for the current activity. Consequently, not only Malaga is technically efficient $(82.35 \%$ in 2009), but this efficiency makes the airport to become also profitable accounting efficient ( +34.01 million of euro). After the new terminal is opened in 2010, Malaga increases significantly the expense per depreciation $(+124 \%)$. The fact that the number of passengers is similar in the following years, the new terminal makes the airport to become not profitable across years (the gross margin decreases in -161\% from 2009 to 2010), and also to drop its efficiency progressively (65.72\% in 2010; 62.90\% in 2011; 55.08\% in 2012): Malaga airport ends up with an excess of capacity as a result of wrong investment decisions made by the central Government not required to attend the actual and future demand 22

As it has been seeing, the depreciation of the airport infrastructure is the most plausible explanations for most of the Spanish airports to become not only no-profitable, but also technically inefficient: these are airports with capacity not used in their main activity (over-capacity). The negative impact of the depreciation is more significant when airports

22 The new regulatory framework (IFRSs; IASs and ISAs) states that a non-current asset should be depreciated as soon as it is ready to be used (not when it is starting to be used). With this regard, the new terminal should have been depreciated in 2009 when it was finished instead of in 2010 when it was used (open). Consequently in 2009, Malaga would be also no-profitable. 
have a reduce number of airlines (or number of routes) operating on them. Again, due to a high standardization of decisions, which are centralised, airports do not have flexibility to negotiate with airlines and therefore, the more capacity the airports have the more technically inefficient become unless there is a bias from aeronautical revenues to commercial activities.

Barcelona also has a significant negative impact due to the investments made to expand the airport and not to use the over-capacity to increase the traffic. In 2009 the charge per depreciation represents a $59.38 \%$ of its aeronautical revenues. Considering that Madrid has a significant bigger size (more infrastructure) and the charge per depreciation is the $67.13 \%$ of its aeronautical revenues, it seems that the investment made in Barcelona to build the new terminal is excessive for its current demand. Barcelona opens its new terminal in June 2009 resulting in a $26 \%$ more in terms of depreciation due to the new building. The number of passengers merely increases from 2009 to 2012 being the most significant increase $+17.68 \%$ from 2010 to 2011 (the average increment is $+28.05 \%$; and specifically $+6.45 \%$ from 2009 to 2010 ; $+2.21 \%$ 2011-12; +0.26\% 2012-13). In consequence, Barcelona becomes progressively a no-profitable airport essentially in 2009 and 2010 (the gross margin drops in $-127 \%$ ). Nevertheless, although there is not a significant increase in the number of passengers, the efficiency level of Barcelona airport seems not to be affected though, showing high efficiency levels in all the years (average of $86.35 \%$ ). The forecast for the airport with the new terminal was settled in 55 million of passengers. The old terminal in 2009 had a capacity for 30.0 million passengers, therefore it seems that based on the current demand (in average 31.5 million from 2009 to 2012) Barcelona airport would have had enough with expanding the old terminal instead of building a new one. The impact of this investment is making Barcelona a no-profitable airport since the main reason behind its negative gross margin is the expense per depreciation. The discussion is around if this new terminal becomes effectively and idle resource to Barcelona: the fact that the efficiency scores do not change and Barcelona is almost technically efficient, is due to increasing significantly the aeronautical income from 2010 to 2012 (43\% from 2010 to $2011 ; 36 \%$ from 2011 to 2012), but these increments cannot be explained based on the number of passengers which remain overall similar to previous years. The regression when explaining the aeronautical income shows that the passengers are not significant $(P>|t|=0.067$ ) (see Table 5)

Barcelona does not experiment an increase in demand. Therefore, the increase in aeronautical revenues $(+43 \%$ from 2010 to 2011), cannot be explained by the number of passengers. Additionally Barcelona has also higher costs due to depreciation of the new terminal: why Barcelona is technically efficient then? This is the consequence of the fees policy applied by AENA from 2010 to 2011. The aeronautical fees are increased in two step process and these fees are to be paid by the operating airlines, ending up in more aeronautical revenues for the airports. The first increment is on the $1^{\text {st }}$ of January 2011 applying a minimum charge of landing fee (Law 39/2010, $22^{\text {nd }}$ December). The second increment is applied in June (Law 1/2011, $4^{\text {th }}$ of March) based on the National Plan for Air Safety (Civil Aviation). These two increments of aeronautical fees are mainly focused on changes in landing fees; route tax as well as the parking fee for the aircrafts. Overall the changes in fees implies for some airports increases to the extent of $2,800 \%$ (ACETA, October 2011. ACETA on behalf of its members-Spanish airlines shows the disagreement with the increments of fees, 3th April 2012) 23 For Barcelona the increase in fees is 2,116\% and for Madrid 2,767\% (ACETA, October 2011).

The increase in the fees to the airlines makes the aeronautical income to increase significantly to the extent of making Barcelona technically efficient even having idle resources: the new terminal building should expand the current capacity to a total of 55 million passengers but, it is only used in a $57.29 \%$ (31.5 million in average from 2009 to 2012). It could be concluded that the increase in aeronautical income does not provide a fair and true view of the current efficiency of Barcelona airport since Barcelona airport is not using its whole capacity (forecast of 55 million passengers per year). By extension, the increase of $152 \%$ in the gross margin from 2010 to 2011 is not a fair view of how Barcelona is performing. The aeronautical revenues do not increase based on attracting higher number of passengers, but because AENA has increased significantly the fares to airlines: the variation in the gross margin from 2009 to 2010 (before the new fees are applied to the airlines) experiments a decrease of $-127 \%$ mainly explained by the charge per depreciation of the new terminal building. The aeronautical income experiments a low increase of $+6 \%$ between 2009 and 2010. Nevertheless in 2010 AENA changes significantly the fees to be charged to the airlines $(2,116 \%$ ACETA, 2011) making the aeronautical income to increase in a $+43 \%$ and the gross margin in a $+152 \%$ and Barcelona to become profitable. As it is seen, there is not consistency in the gross margins across the years for airport such as Barcelona, Madrid or Malaga (see Table 4). Since profitable airports must cross-subsidize no-profitable airports, the findings demonstrate that the Spanish Airport-System is not sustainable any more. Not only the Spanish airports are overall no profitable, but the gross margins are not reflecting a true and fair view of the airports performance since the positive margins are the result of fare and regulation policies which are not in accordance with the actual reality of the Spanish Airport-System. Additionally, the fact that the airports are not using the full capacity due to excessive investment decisions (over-investments) makes the Spanish airports to become also technically inefficient.

This plastic improvement in the aeronautical income has two effects: 1) Barcelona becomes a profitable airport with a gross margin of +45.12 in 2011 ; 2) Barcelona becomes an efficient airport because the increase in the aeronautical revenues should be a reflection that the airport is using most of its current capacity in the ordinary course of business. Both improvements, in the gross margin and the efficiency

23 ACETA-Asociacion de Compañias Areas de Transporte Aereo. 
are not the true and fair view of this airport. Barcelona is not achieving high values of gross margin because is performing well because is attracting more passengers and therefore more aeronautical income is earned, but because AENA has regulated the taxes (fees) to an extreme value that represents a significant increase in aeronautical income especially from 2010 to 2011 ( $+43 \%$ for Barcelona; $+28 \%$ for Madrid).

A similar analysis can be performed to Madrid-Barajas. From 2010 to 2011 the increase in the aeronautical fees is 2,767\% (ACETA, 2011). These represent an improvement of $189 \%$ in Madrid's previous gross margin changing from being a no-profitable airport (-82.73 million) to achieve a positive gross margin in 2011 (73.44 million). In 2009 the gross margin was extremely negative (-121.30 million) demonstrating that any improvement from January 2010 onwards cannot be related to improvements in the airport activity and therefore in its efficiency. Indeed, from 2009 to 2012 the number of passengers in average is 48.3 million; there is not significant changes in each year $(+2.95 \%$ from 2009 to $2010 ;-0.39 \%$ from 2010 to $2011 ;-9.02 \%$ from 2011 to 2012 and $-12.07 \%$ from 2011 to 2012). Overall the number of passengers has decreased in $17.96 \%$ between 2009 and 2012, but the aeronautical income increases significantly in a $28 \%$ (from 2010 to 2011 ) and in $18 \%$ (from 2011 to 2012). The change in the revenues between 2009 and 2010 is an increase of $2 \%$.

Regarding efficiency, Madrid is one of the airports more technically efficient becoming frontier (score of 100\%) in 2011 and 2012 (see Table 2). The efficiency should be achieved on the base of the full usage of the airport capacity to develop the main activity. Nevertheless the fact that the number of passengers do not change significantly across the years indicates that the increase in the aeronautical income is due to the changes in fees applied by AENA. Consequently the fact that Madrid is efficient, it is not because how well used its resources to increase the level output (for instance attracting more passengers per year), but because the aeronautical revenues are due to airport fees significantly increased from 2011 compared to 2010 or 2009 . Furthermore, these revenues will also affect to the changes in gross margins across years, meaning that the fact that the airport becomes profitable cannot be the result of a better performance, but again due to increasing fees by AENA.

Finally the decrease shown in the charge per depreciation of some airports from 2010 to 2012, even after being expanded also enhances the achievement of higher gross margins. It is necessary to evaluate if the changes in depreciation charges respond to the reality of the airport activity rather than decisions to improve how the income statement looks like. For example, for Barcelona the charge per depreciation increases in $+26 \%$ from 2009 to 2010, this corresponds to the new terminal building, but then from 2010 to 2011 the variation in depreciation is only $+1 \%$ and even a decrease in $-2 \%$ from 2011 to 2012 . Malaga experiments a significant increase in the expense per depreciation of + $124 \%$ from 2009 to 2010 , but then only $+24 \%(2010-11)$ and $+10 \%$ (2011-12). The reduction in the depreciation charge (expense accrued) makes the gross margin to become more positive, and therefore the airport more profitable. These variations are extremely inconsistent and not justified: again the improvements in the gross margins of the airports are not real, but due to potential changes in percentages of depreciation applied instead of using a constant fixed rate 24 .

The entitlement of AENA to act on behalf of the Government to change fares opens a discussion regarding the transparency of the management process and the Spanish Airport-System is the best option to enhance a competitive market. It is highlighted the need of having independent regulators to regulate the fees (for instance when power-market is detected) or independent bodies to supervise the changes in fees applied by AENA. The Board for competition's report (CNMC, July 2014) stresses that to join ownership and regulation could end in defending the regulator's aims rather than the market's. The policy of increasing aeronautical fees to the extent of no-profitable major airports (such as Barcelona and Madrid) becoming profitable is not a solution for an airport-system to be sustainable in the long-term. Not only is necessary to evaluate the truly main reasons for airports being not profitable; but to make decisions in accordance to the way airports' develop the operational activity in order to improve their actual performance. It is necessary to question if these changes in the aeronautical taxes allow airports to be competitive; to attract airlines and therefore potential future passengers in order to have a full usage of capacity (to be fairly efficient). And, also if these fees reflect the reality of the business, this is if the airports' gross margin (positive or negative) is the result of performing and improving the aeronautical activity (increase of flights and increase in passengers) rather than a result of an increase in charges to the airlines.

The Board for regulation in airports and railways (CRFA, 90) based on the amends to the regulatory framework from 2011 (Law 11/2011 26 $6^{\text {th }}$ of August), acts as an temporary independent supervisor to confirm if the changes and capitalisation of the airport fees would ensure the efficiency of airports as well as the sustainability of all the airports (the Spanish Airport-System). In the report's Board $\left(12^{\text {th }}\right.$ September 2013), it is requested a change in the fee policy applied by AENA in 2014 and also a price-cap. The idea of using a price-cap is to incentive the entry of new operators (airlines) to airports and also to provide stability for the current airlines. A public price-cap is a warranty for airlines that prices (fees) will not change in a certain period of time, and therefore a lower constraint for airlines to entry into the market. By extension it also provides stability for airports by knowing with certainty the airlines that will provide or will be willing to continue providing services during that specific period of time. There are some regulators well-known

24 This could be indicating that AENA dictates a decreasing method of depreciation instead straight line (the same amount per year) applying higher charges at the beginning of the usage of the infrastructure and less and the last years. Although this is a method approved by the international accounting standards (IASs, 2008), this method seems not to correspond to how the airport activity is developed: any method of depreciation should reflect the relation between the income earned and the expenses incurred. The expansion plans are based on a forecasting of potential passengers in the long-term (three-four years) not in the short term. Consequently, if there are more aeronautical revenues in the last years (2012 compared to 2009) the depreciation should be the other way round, less charge at the beginning of usage and more in the most recent years. 
worldwide in the UK; Ireland and The Netherlands. The Civil Authority Aviation (CAA) is the independent regulatory body in the UK aviation industry (1972). One example of the price-cap regulation has been announced in January 2014 forbidding Heathrow airport to increase the charges more than the inflation rate (Heathrow asked for an increase of $4.6 \%$ above the inflation rate). The CAA has confirmed that price rises will be limited to $1.5 \%$ below inflation for the next five years, starting in April 2014. Again the CAA has decided not to regulate the prices established by Stansted airport since it does not have substantial market power (BBC, January 2014)

In the Spanish aviation industry, the new regulation with effect March 2014 (CRFA, 2013) establishes a maximum increment of $2.5 \%$ being a $4.5 \%$ for 2015 and to a cap-price of $5.5 \%$ in the following three years (until 2018). The idea of this new regulation is to incentive airlines to operate in the market. The Board for competition (CNMC, 2014) has approved the proposal from AENA not to change the airport fees for 2015. Although this AENA's commitment will certainly help to show a fair view of the Spanish Airport-System from the economic perspective (financial statements), the technical efficiency will not improve unless the Spanish airports use their current capacity (infrastructure) to develop their operational activity. It is necessary to accelerate the negotiation process with airlines, and this means to allow the individual management of the Spanish airports to be flexible regarding certain decisions including the policies regarding depreciation of the assets.

The results for the second DEA applied to medium airports are shown in the next table:

Table 6. DEA-Output Medium airports (2009-2012)

\begin{tabular}{cccccc}
\hline & Average & 2012 & 2011 & 2010 & 2009 \\
\hline Murcia & $92.36 \%$ & $89.50 \%$ & $84.97 \%$ & $94.95 \%$ & $100.00 \%$ \\
Santander & $89.21 \%$ & $76.40 \%$ & $88.46 \%$ & $91.97 \%$ & $100.00 \%$ \\
Granada-Jaen & $81.62 \%$ & $67.19 \%$ & $95.09 \%$ & $81.56 \%$ & $82.64 \%$ \\
Asturias & $80.14 \%$ & $74.02 \%$ & $72.48 \%$ & $89.13 \%$ & $84.92 \%$ \\
A Coruña & $79.51 \%$ & $68.25 \%$ & $69.11 \%$ & $80.67 \%$ & $100.00 \%$ \\
Vigo & $78.01 \%$ & $60.13 \%$ & $66.99 \%$ & $91.89 \%$ & $93.03 \%$ \\
Girona-Costa & $77.11 \%$ & $57.68 \%$ & $61.78 \%$ & $88.99 \%$ & $100.00 \%$ \\
Brava & $75.86 \%$ & $46.21 \%$ & $70.88 \%$ & $89.64 \%$ & $96.70 \%$ \\
Santiago & $75.84 \%$ & $59.29 \%$ & $71.72 \%$ & $79.26 \%$ & $93.08 \%$ \\
Jerez & $75.20 \%$ & $57.88 \%$ & $65.95 \%$ & $76.98 \%$ & $100.00 \%$ \\
Menorca & $72.71 \%$ & $61.20 \%$ & $69.05 \%$ & $83.56 \%$ & $77.03 \%$ \\
Reus & $67.68 \%$ & $58.54 \%$ & $65.09 \%$ & $72.32 \%$ & $74.78 \%$ \\
Almeria & $63.80 \%$ & $48.35 \%$ & $55.69 \%$ & $72.22 \%$ & $78.96 \%$ \\
La Palma & & & & &
\end{tabular}

The correlation matrix between the inputs and outputs for medium airports shows that there is a slightly relation between the usage of the infrastructure (depreciation) and the activity performed measured through the aeronautical income $(+0.5098)$. Cargo shows a relatively high correlation with the charge per depreciation $(+0.7035)$, indicating that airports with more infrastructure will also have more cargo (more belts; bigger warehouses where to allocate the cargo, etc.). But since cargo does not affect either aeronautical
$(+0.3640)$ or commercial income $(+0.2508)$, the fact that an airport has more capacity does not ensure to achieve more revenues. The charge per depreciation has a high correlation with other operating costs $(+0.8285)$ as well as wages $(+0.8415)$ showing that the bigger the airport regarding capacity (infrastructure) the more likely to incur in higher operational costs indirectly related to the airport activity (utilities; rent, etc.) as well as employee costs. The charge per depreciation and the revenues are slightly related in the case of medium airports $(+0.5098$ for aeronautical and +0.4620 for commercial), indicating the fact that an airport has more infrastructure does not ensure to achieve higher revenues compared to other airports with less capacity. Indeed, airports earn revenues based on the number of passengers and therefore, depending on the number and type of airlines operating on them, as well as the decision power to attract other airlines or new routes to be covered by the operating airlines. This is also confirmed by the high correlation between the number of passengers and both type of revenues (aeronautical +0.9577 ; commercial +9474 ).

The airports that achieve higher efficiency scores are Murcia and Santander. These two airports are the ones with less cargo and relatively medium number of passengers compared to the other medium airports for all the years of the study. The rest of the airports achieve efficiencies between $64 \%-82 \%$. The airports that show more variability in their scores are A Coruna; Girona and Menorca than after being frontier (100\% efficient) in 2009 experiment a significant decrease in their efficiency levels. Overall all the medium airports have negative gross margins in the period of study. Girona is the only airport that achieves significant positive gross margins in $2009(+23.90$ million of euro) and in 2010 $(+17.63)$

Table 7. Gross margin Medium Airports

\begin{tabular}{ccccc}
\hline & 2012 & 2011 & 2010 & 2009 \\
\hline A Coruña & -11.34 & -11.06 & -6.78 & -2.51 \\
Almeria & -14.20 & -12.54 & -9.40 & -8.02 \\
Asturias & -4.66 & -6.55 & -1.51 & -2.86 \\
Girona-Costa & -3.48 & -3.75 & 17.63 & 23.90 \\
Brava & -11.89 & -4.64 & -7.24 & -5.86 \\
Granada-Jaen & -15.99 & -11.80 & -7.25 & -4.32 \\
Jerez & -27.93 & -25.20 & -17.42 & -16.01 \\
La Palma & -15.79 & -14.82 & -14.60 & -18.76 \\
Menorca & -2.60 & -4.60 & -1.82 & 0.90 \\
Murcia & -13.46 & -9.68 & -5.89 & -6.55 \\
Reus & -6.52 & -5.56 & -6.35 & -4.32 \\
Santander & -30.14 & -9.89 & -4.87 & -3.90 \\
Santiago & -16.69 & -18.64 & -7.35 & -6.01 \\
Vigo & & & & \\
\hline
\end{tabular}

The medium airports seems to decrease their gross margin progressively and especially in 2011 and 2012. All the airports experiment a decrease in the number of passengers from 2011 to 2012 except Santander $(+16.64 \%)$. Again, all the airports drop their efficiency levels from 2009 to 2012. The next table shows the average of efficiency achieve by the medium airports from 2009 to 2012, compared to the change in the number of passengers and the change in efficiency 
between these two years, as well as the average of cargo across the years and the variation between 2009 and 2012 .

These results show that for medium airports, the lower average of cargo the more technical efficiency the airports become. The correlation matrix of these values shows a high and negative correlation between the average of cargo in the airports from 2009 to 2012 and the changes in efficiency $(-0.7011)$. This correlation indicates that when airports have more cargo across the years, their technical efficiency level seems to be dropped. This is also confirmed by the regression of the average of efficiency to be explained by the variation in passengers, cargo and the average of cargo. The only significant variable is the average of cargo $(P>|t|=$ 0.030 ) with a negative regression coefficient. The changes in the number of passengers is not significant, indicating that the fact that the airports have drop their efficiency scores from 2009 to 2012 is not due to a decrease in the demand.
Linking with the fee policy applied by AENA from 2011, the increase in fees to the airlines could explain that airports do not perform as well as before these fees.

The regression of the efficiency scores with all the inputs and outputs (see Table 9), shows that the number of passengers does not affect the technical efficiency $(P>$ $|t|=0.609)$, but cargo $(P>|t|=0.000)$ does as well as the costs of developing the ordinary course of business (wages of employees; depreciation of assets and other operating costs). This findings evidence that changes in the number of passengers do not affect the efficiency scores for medium airports. The decrease in the number of passengers could be explained by choosing alternative methods of travelling after the announcement of the increment of fees by AENA. Further analysis would be conducted in future studies to evaluate the impact of tourism variables in the Spanish airports' actual efficiency.

Table 8. Efficiency, passengers and cargo Medium Airports (2009-2012)

\begin{tabular}{|c|c|c|c|c|c|}
\hline & Average Efficiency & $\Delta$ Efficiency & $\triangle \mathrm{MPAX}$ & Average Cargo & $\Delta$ Cargo \\
\hline A Coruña & $79.51 \%$ & $-31.75 \%$ & $-20.90 \%$ & 233,023 & $-44,078$ \\
\hline Almeria & $67.68 \%$ & $-16.23 \%$ & $-5.32 \%$ & 12,195 & $-7,606$ \\
\hline Asturias & $80.14 \%$ & $-10.91 \%$ & $-0.49 \%$ & 115,587 & $-11,367$ \\
\hline Girona-Costa Brava & $77.11 \%$ & $-42.32 \%$ & $-46.20 \%$ & 82,835 & 62,842 \\
\hline Granada-Jaen & $81.62 \%$ & -0.15 & $-38.67 \%$ & 35,361 & $-13,217$ \\
\hline Jerez & $75.84 \%$ & $-33.80 \%$ & $-15.40 \%$ & 84,109 & $-88,093$ \\
\hline La Palma & $63.80 \%$ & $-30.61 \%$ & $-7.43 \%$ & 890,893 & $-397,394$ \\
\hline Menorca & $75.20 \%$ & $-42.12 \%$ & $4.61 \%$ & $2,221,441$ & $-828,363$ \\
\hline Murcia & $92.36 \%$ & $-10.50 \%$ & $-27.53 \%$ & 3,201 & $-8,403$ \\
\hline Reus & $72.71 \%$ & $-15.83 \%$ & $-45.08 \%$ & 76,413 & 5,584 \\
\hline Santander & $89.21 \%$ & $-23.60 \%$ & $16.64 \%$ & 3,854 & $-10,000$ \\
\hline Santiago & $75.86 \%$ & $-50.49 \%$ & $12.89 \%$ & $1,889,084$ & $-172,801$ \\
\hline Vigo & $78.01 \%$ & $-32.90 \%$ & $-24.89 \%$ & 845,619 & $-225,820$ \\
\hline
\end{tabular}

Table 9. Regression Efficiency Medium-Airports

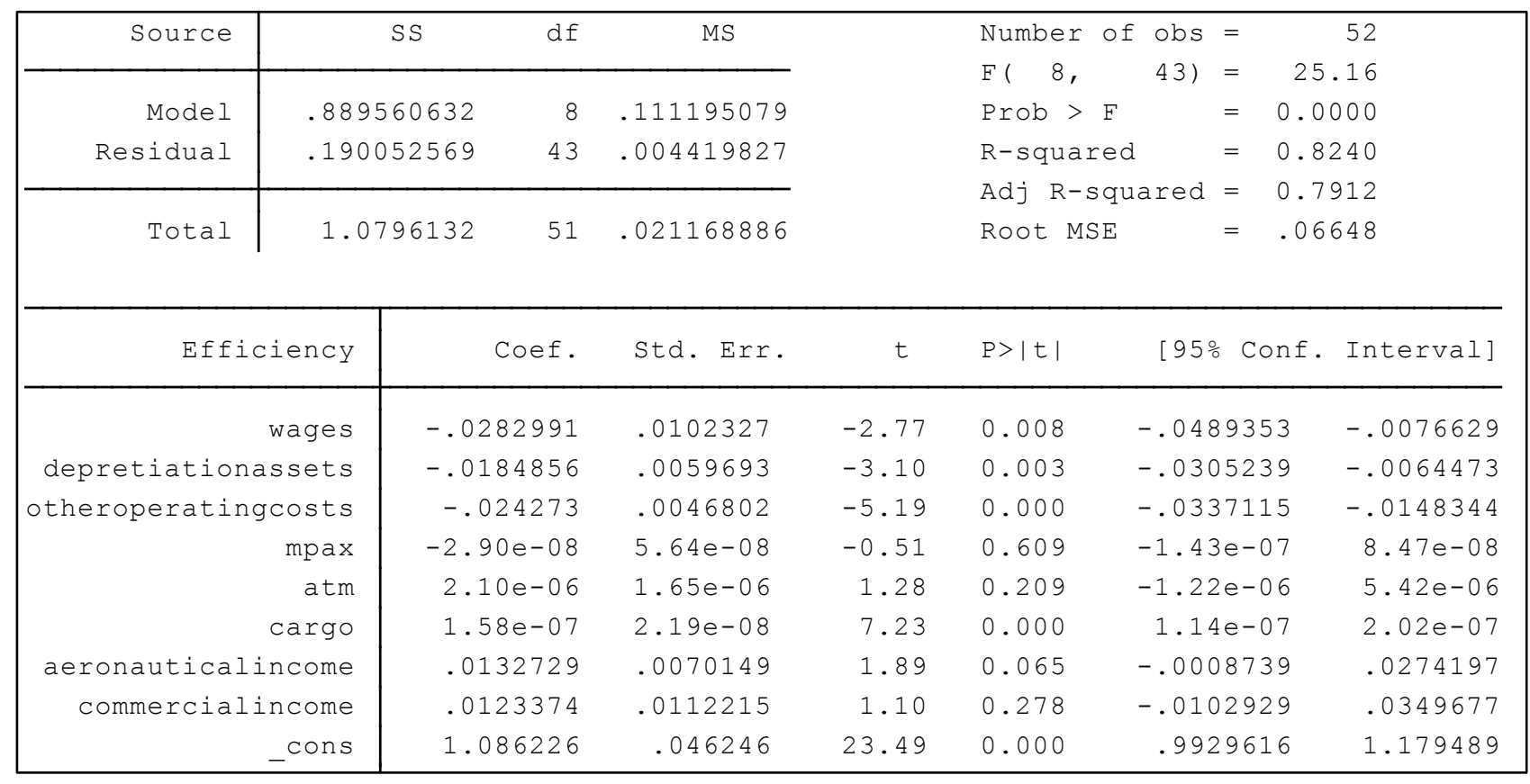


Table 10. DEA-Output Small airports (2009-2012)

\begin{tabular}{|c|c|c|c|c|c|}
\hline & Average & 2012 & 2011 & 2010 & 2009 \\
\hline Zaragoza & $96.31 \%$ & $100.00 \%$ & $100.00 \%$ & $100.00 \%$ & $85.22 \%$ \\
\hline Son Bonet & $95.57 \%$ & $100.00 \%$ & $100.00 \%$ & $99.32 \%$ & $82.97 \%$ \\
\hline Ceuta & $87.98 \%$ & $100.00 \%$ & $91.49 \%$ & $81.40 \%$ & $79.02 \%$ \\
\hline San Sebastian & $80.72 \%$ & $66.58 \%$ & $68.57 \%$ & $87.74 \%$ & $100.00 \%$ \\
\hline Madrid 4 vientos & $79.15 \%$ & $52.01 \%$ & $66.07 \%$ & $98.51 \%$ & $100.00 \%$ \\
\hline Huesca-Pirineos & $77.09 \%$ & $89.37 \%$ & $63.02 \%$ & $69.63 \%$ & $86.33 \%$ \\
\hline Albacete & $77.04 \%$ & $76.64 \%$ & $77.61 \%$ & $76.00 \%$ & $77.92 \%$ \\
\hline Badajoz & $75.36 \%$ & $61.20 \%$ & $50.22 \%$ & $90.03 \%$ & $100.00 \%$ \\
\hline Valladolid & $75.26 \%$ & $59.29 \%$ & $67.60 \%$ & $89.24 \%$ & $84.90 \%$ \\
\hline Burgos & $73.00 \%$ & $78.45 \%$ & $63.60 \%$ & $72.19 \%$ & $77.76 \%$ \\
\hline Sabadell & $69.22 \%$ & $38.82 \%$ & $54.48 \%$ & $83.57 \%$ & $100.00 \%$ \\
\hline Pamplona & $61.28 \%$ & $38.75 \%$ & $47.54 \%$ & $74.70 \%$ & $84.14 \%$ \\
\hline Cordoba & $58.73 \%$ & $71.01 \%$ & $55.53 \%$ & $52.33 \%$ & $56.05 \%$ \\
\hline Leon & $54.38 \%$ & $47.29 \%$ & $59.11 \%$ & $49.05 \%$ & $62.05 \%$ \\
\hline Madrid Torrejon & $54.00 \%$ & $35.63 \%$ & $37.84 \%$ & $61.86 \%$ & $80.65 \%$ \\
\hline Salamanca & $53.65 \%$ & $33.95 \%$ & $38.55 \%$ & $71.01 \%$ & $71.09 \%$ \\
\hline La Gomera & $52.12 \%$ & $56.63 \%$ & $54.39 \%$ & $46.95 \%$ & $50.49 \%$ \\
\hline El Hierro & $49.75 \%$ & $41.98 \%$ & $42.07 \%$ & $56.86 \%$ & $58.08 \%$ \\
\hline Vitoria & $44.95 \%$ & $39.99 \%$ & $48.20 \%$ & $44.41 \%$ & $47.20 \%$ \\
\hline Melilla & $44.87 \%$ & $34.97 \%$ & $41.06 \%$ & $54.00 \%$ & $49.46 \%$ \\
\hline Logrono & $42.15 \%$ & $28.69 \%$ & $34.91 \%$ & $51.50 \%$ & $53.49 \%$ \\
\hline
\end{tabular}

Finally, the last DEA applied to small airports shows that the most efficient airports with less variability are Zaragoza, Son Bonet and Ceuta.

Zaragoza is one of the airports with more number of passengers and also cargo across the years of the study. Ceuta is a heliport, likely not to be restricted to air traffic control. In average all the small airports have negative gross margin. Overall small airports seem to achieve reasonable technical efficiency scores that it is consistent across the years, because they tend to use their current capacity (airport infrastructure) for their operational activity. Nevertheless small airports are not economic efficient and therefore they represent a loss of financial resources (bias) from profitable airports (normally big airports) to them. Additionally the fact that most of the small airports are located close to each other (within the catchment area), highlights the discussion regarding why these small airports should be opened to attend the current demand if these routes could be absorbed by bigger airports which could achieve not only higher accounting results, but essentially to have a better use of their infrastructure (technically efficient).

The Spanish Airport-System agglomerates 21 small airports (with not more than 750,000 passengers per year) compared to 14 big airports (more than 3,500,000 passengers per year) and 13 medium. All small airports have a negative average of EBIDTA from 2009 to 2012; this is even before considering the depreciation expense. For the medium airports, only four achieve a positive EBIDTA, but with a significant small values except for Girona. After deducting the depreciation, all medium airports have negative operational results except Girona. Finally, all big airports have positive EBIDTAs and due to the significant number of passengers are able to earn significant revenues to cover their operating costs, except Malaga (due to the expansion in capacity which has not implied a correlate increase in the number of passengers) and Tenerife South located within the same catchment area that Tenerife North. It is interesting to notice that due to over-investments in capacity in airports such as Madrid and Barcelona, these incur in significant financial expenses being respectively $284 \%$ and $59 \%$ of their operating result. The financial expenses accrued make Madrid to become a no-profitable airport although being on the most technical efficient airports since it is the only international interconnector (hub).

Summarizing, only the biggest airports and one medium airport (Girona) are profitable obligated to subsidize the rest implicating that the Spanish Airport-System is unsustainable in the long term. Although some big airports experiment increases in the revenues due to significant increases in the air fares applied by the Government, these happen at the same time that expansions are made, but the average of passengers remains similar across the years resulting in over-investments or idle infrastructure. Overall the results show that big airports are capable of generating enough income through their operational airport activity to cover their operating costs, but they must sacrifice financial resources to support the Spanish Airport-System. This does not mean that the effect of wrong investments decisions by 
the Government has been evaluated yet, but it needs to be evaluated in the long-term.

Regarding if the Spanish Airport-System allows competition in the national market, airports seem to be more technically efficient with similar size airports (with similar number of passengers). The change in efficiency when competing in clusters compared to operating altogether are summarize in Table 11. The efficiency scores disclosed from 2009 to 2012 shows the efficiency level achieved by the airports when competing with airports similar to them (clusters). For instance, for the larger airports, Palma de Mallorca is the most efficient airport with an average score of $96.52 \%$ and Malaga is the less efficient with an average of $66.51 \%$. For medium airports, Murcia is the most technically efficient with an average of $92.36 \%$ and La Palma the least efficient with $63.80 \%$. Finally when small airports compete together, Zaragoza, Son Bonet and Ceuta are the most efficient.

Comparing these scores with the technical efficiency achieved when there is no distinction between big, medium and small airports, the column of variation in efficiency shows that most of them increase their efficiency when competing with other airports that are similar in size: airports are less efficient when performing altogether in the same market). The increase in efficiency is relevant for the medium airports which experiment increases from $30 \%$ to $60 \%$. The exception is Girona with only an increase in technical efficiency around $8 \%$ when operating with similar airports. With this regard, Girona seems to be more efficient when competing with larger airports. One of the most reasonable explanations is Girona becoming an alternative airport to attend the demand willing to visit or travel to Girona, but with flights to Barcelona and due to being in the same catchment area (one hour driving). This process starts happening from the beginning of 2011 when the low-cost airline Ryanair reduced significantly most of the services in Girona and transfer them to Barcelona airport. Small airports show more variability regarding changing in efficiency scores. Overall small airports increase their efficiency between $1 \%$ and $20 \%$ and from $38 \%$ to $52 \%$ for the three airports with higher number of passengers (San Sebastian, Valladolid and Pamplona). The larger airports increase their efficiencies between 5\% and 30\% except for Barcelona (1\%); Malaga (3\%); Madrid (1\%) and Palma de Mallorca that a very small lost in efficiency (-1\%). Regarding Barcelona and Malaga, the low improvements in efficiency could be explained by the expansion of capacity that has become an idle resource for these airports. Madrid is an outlier since it is the only hub in Spain. Overall all the airports gain in technical efficiency when operating with airports with similar passengers suggesting that tailored management decisions should also be made regarding the different current needs and demand of each group of airports. 
Table 11. Variation in efficiency: competition with similar airports (clusters)

\begin{tabular}{|c|c|c|c|c|c|c|c|c|c|c|c|c|c|}
\hline & $\Delta$ Efficiency & Average & 2012 & 2011 & 2010 & 2009 & \multicolumn{2}{|c|}{$\Delta$ Efficiency } & Average & 2012 & 2011 & 2010 & 2009 \\
\hline Palma de Mallorca & $-0.46 \%$ & $96.52 \%$ & 0.8792 & 0.9897 & 0.9919 & 1.0000 & Reus & $38.01 \%$ & $72.71 \%$ & 0.6120 & 0.6905 & 0.8356 & 0.7703 \\
\hline Madrid Barajas & $0.28 \%$ & $96.41 \%$ & 1.0000 & 1.0000 & 0.9628 & 0.8936 & Almeria & $44.12 \%$ & $67.68 \%$ & 0.5854 & 0.6509 & 0.7232 & 0.7478 \\
\hline Gran Canaria & $2.68 \%$ & $91.06 \%$ & 0.7705 & 0.9437 & 0.9478 & 0.9804 & La Palma & $42.54 \%$ & $63.80 \%$ & 0.4835 & 0.5569 & 0.7222 & 0.7896 \\
\hline Lanzarote & $21.33 \%$ & $89.80 \%$ & 0.7278 & 0.9243 & 0.9692 & 0.9707 & Zaragoza & $13.70 \%$ & $96.31 \%$ & 1.0000 & 1.0000 & 1.0000 & 0.8522 \\
\hline Bilbao & $22.21 \%$ & $89.73 \%$ & 0.7200 & 0.9211 & 0.9481 & 1.0000 & Son Bonet & $9.44 \%$ & $95.57 \%$ & 1.0000 & 1.0000 & 0.9932 & 0.8297 \\
\hline Tenerife North & $19.63 \%$ & $88.57 \%$ & 0.6727 & 0.8902 & 0.9799 & 1.0000 & Ceuta & $0.91 \%$ & $87.98 \%$ & 1.0000 & 0.9149 & 0.8140 & 0.7902 \\
\hline Fuerteventura & $30.51 \%$ & $88.50 \%$ & 0.6879 & 0.8558 & 0.9963 & 1.0000 & San Sebastian & $52.31 \%$ & $80.72 \%$ & 0.6658 & 0.6857 & 0.8774 & 1.0000 \\
\hline Valencia & $11.03 \%$ & $88.40 \%$ & 0.6661 & 0.8776 & 0.9923 & 1.0000 & Madrid 4 vientos & $9.64 \%$ & $79.15 \%$ & 0.5201 & 0.6607 & 0.9851 & 1.0000 \\
\hline Barcelona & $0.37 \%$ & $86.35 \%$ & 0.8872 & 0.9108 & 0.8125 & 0.8436 & Huesca-Pirineos & $14.99 \%$ & $77.09 \%$ & 0.8937 & 0.6302 & 0.6963 & 0.8633 \\
\hline Ibiza & $16.83 \%$ & $82.95 \%$ & 0.6986 & 0.8542 & 0.8880 & 0.8770 & Albacete & $4.75 \%$ & $77.04 \%$ & 0.7664 & 0.7761 & 0.7600 & 0.7792 \\
\hline Alicante & $4.97 \%$ & $80.49 \%$ & 0.5611 & 0.7394 & 0.9267 & 0.9924 & Badajoz & $-4.41 \%$ & $75.36 \%$ & 0.6120 & 0.5022 & 0.9003 & 1.0000 \\
\hline Seville & $15.65 \%$ & $76.21 \%$ & 0.6479 & 0.7862 & 0.7916 & 0.8225 & Valladolid & $48.76 \%$ & $75.26 \%$ & 0.5929 & 0.6760 & 0.8924 & 0.8490 \\
\hline Tenerife South & $5.52 \%$ & $69.52 \%$ & 0.5997 & 0.7481 & 0.7092 & 0.7236 & Burgos & $13.57 \%$ & $73.00 \%$ & 0.7845 & 0.6360 & 0.7219 & 0.7776 \\
\hline Malaga & $2.55 \%$ & $66.51 \%$ & 0.5508 & 0.6290 & 0.6572 & 0.8235 & Sabadell & $-6.41 \%$ & $69.22 \%$ & 0.3882 & 0.5448 & 0.8357 & 1.0000 \\
\hline Murcia & $57.51 \%$ & $92.36 \%$ & 0.8950 & 0.8497 & 0.9495 & 1.0000 & Pamplona & $37.50 \%$ & $61.28 \%$ & 0.3875 & 0.4754 & 0.7470 & 0.8414 \\
\hline Santander & $58.59 \%$ & $89.21 \%$ & 0.7640 & 0.8846 & 0.9197 & 1.0000 & Cordoba & $10.56 \%$ & $58.73 \%$ & 0.7101 & 0.5553 & 0.5233 & 0.5605 \\
\hline Granada-Jaen & $56.03 \%$ & $81.62 \%$ & 0.6719 & 0.9509 & 0.8156 & 0.8264 & Leon & $21.80 \%$ & $54.38 \%$ & 0.4729 & 0.5911 & 0.4905 & 0.6205 \\
\hline Asturias & $51.72 \%$ & $80.14 \%$ & 0.7402 & 0.7248 & 0.8913 & 0.8492 & Madrid Torrejon & $8.05 \%$ & $54.00 \%$ & 0.3563 & 0.3784 & 0.6186 & 0.8065 \\
\hline A Coruña & $52.01 \%$ & $79.51 \%$ & 0.6825 & 0.6911 & 0.8067 & 1.0000 & Salamanca & $5.82 \%$ & $53.65 \%$ & 0.3395 & 0.3855 & 0.7101 & 0.7109 \\
\hline Vigo & $54.20 \%$ & $78.01 \%$ & 0.6013 & 0.6699 & 0.9189 & 0.9303 & La Gomera & $0.73 \%$ & $52.12 \%$ & 0.5663 & 0.5439 & 0.4695 & 0.5049 \\
\hline Girona-Costa Brava & $7.74 \%$ & $77.11 \%$ & 0.5768 & 0.6178 & 0.8899 & 1.0000 & El Hierro & $12.35 \%$ & $49.75 \%$ & 0.4198 & 0.4207 & 0.5686 & 0.5808 \\
\hline Santiago & $45.42 \%$ & $75.86 \%$ & 0.4621 & 0.7088 & 0.8964 & 0.9670 & Vitoria & $16.38 \%$ & $44.95 \%$ & 0.3999 & 0.4820 & 0.4441 & 0.4720 \\
\hline Jerez & $30.55 \%$ & $75.84 \%$ & 0.5929 & 0.7172 & 0.7926 & 0.9308 & Melilla & $20.96 \%$ & $44.87 \%$ & 0.3497 & 0.4106 & 0.5400 & 0.4946 \\
\hline Menorca & $42.43 \%$ & $75.20 \%$ & 0.5788 & 0.6595 & 0.7698 & 1.0000 & Logrono & $-2.48 \%$ & $42.15 \%$ & 0.2869 & 0.3491 & 0.5150 & 0.5349 \\
\hline
\end{tabular}




\section{Conclusions and Further Research}

The findings in both technical efficiency and economic performance show that the Spanish Airport-System is not the most adequate to enhance profitability and efficiency as well as competition. In an airport-system profitable airports provide financial resources to not profitable airports (cross-subsidized). An airport-system is sensible in geographical areas where no other alternative models of travelling exists and therefore the Government must ensure that a minimum of transport service is provided by granting the airlines operating in these routes. In the Spanish Airport-System there is a significant number of small airports (21 airports with less than 750,000 passengers per year) compared to medium (13 airports) and big (14 airports with more than $3,500,000$ passengers). All the small airports are not profitable from 2009 to 2012 and only four of them are overall technically efficient. This means that the capacity of these four airports is relatively fully used in the airport operational activity, but not the others. The not profitable small airports represent a loss of financial resources for larger airport which not only are profitable overall, but also achieve high technical efficiency scores. All the big airports have significant values of EBIDTA showing that their operating activity generates enough revenues to cover their operating costs. All the medium airports are not profitable except Girona that has a significant value of EBIDTA. Again, these medium airports are subsidized by the profitable airports representing a bias of income. Overall, only 13 airports show a positive and consistent operational result out of 49 airports across the years of the study.

Centralised decisions regarding excessive investments in infrastructure has ended in idle resources for the most technically efficient biggest airports such as Barcelona, Madrid and Malaga becoming not profitable. The relation between the capacity and the economic efficiency is through the expense per depreciation; the result for the periods when airports have been expanded does not reflect a true and fair view of the economic performance of the Spanish airports. The fact that AENA is entitled to apply regulatory policies regarding air fares and other taxes biases the reality of the Spanish Airport-System. The discriminatory and significant increases in air fares applied from 2011 (especially for Madrid and Barcelona), not only represent a bubble of aeronautical revenues not earned under-covering the excess of investments made and therefore not reflecting a fair and true view of the performance of the Airport industry overall, but also a barrier to attract airlines and potential passengers. The progressive increase in fees is not sustainable in the long-term, airlines tend to change airports depending on the current demand, but also the air fares applied by the airports; the Spanish airports will become even more technically inefficient. Examples of wrong centralised decisions based on excessive expansions that have made airports such Malaga, to become not only not profitable, but also technically inefficient.

Furthermore, since most of the small and medium airports are located within the same catchment areas (one hour driving), the fact that not only are technically inefficient, but also not profitable, encourages to close them down. The Spanish Airport-System would win in economic efficiency (since profitable airports would not need to finance no profitable airports), but also in technical efficiency since airlines, routes and passengers would be transferring to other airports that would see increased their aeronautical revenues and essentially a better use of their infrastructure.

The centralise decision making process is also a factor against competition between airports and consequently, a barrier to attract airlines to operate in them. The results show that big airports achieve positive gross margins consistently due to a significant increase in the aeronautical fees applied by AENA from 2010. The increase in fees has a positive impact in the aeronautical revenues of the airports making them profitable (economic efficient), but this regulatory policy has been decided after expansion plans which do not correspond to the current needs of the airports individually. Furthermore, the increase in aeronautical income has also a positive impact in the technical efficiency of the airports that achieve overall high levels of efficiency. Nevertheless the efficiency scores do not present a fair view of the real performance of the larger airports. The fact that in some airports (Barcelona; Malaga) investments' have expanded the current capacity theoretically, but not in practice by attracting more passengers per year, leads to an over-capacity or idle infrastructure not used for the current level of airport activity. The current capacity used is similar to the airports' capacity before the expansion process starts. Airports that become profitable as well as technically efficient after investments in infrastructure (such as Madrid and Barcelona), correspond to increments in their aeronautical revenues due to extreme increment of fees charges to the airlines. Also, the improvements in gross margins after expanding correspond to aggressive policies of depreciation of assets, incurring in significant higher expenses per depreciation in the first years of the investment being significant lower in the following years 25 . Consequently, both indicators of airports' profitability (gross margin and technically efficiency level) do not show a fair and true view of the Spanish airport industry. The amount of investment is generally decided for those in charge. The main objective of the deregulation process is to improve the financial resources and investment, and their operational efficiency. In the case of the Spanish Airport-System the excess of regulation as well as centralisation ends in a system that becomes inefficient from both economic and technical perspectives, not sustainable in the medium-long terms.

Overall all the airports gain in technical efficiency when operating with airports with similar passengers suggesting the need of tailored management decisions regarding different needs and demand of each group of airports.

25 Unfortunately it has not been possible to find the percentages of deprecation applied by AENA in the notes of the financial statements (annual reports). 
Consequently, the idea of allowing competition between these airports could become an essential managerial decision to help the Spanish Airport-System to become profitable: allowing airports to operate and to compete in order to attract airlines and passengers rather than increasing airports' fees to be charged to airlines or to cross-subsidize not profitable airports.

These results are in accordance to the conclusions drawn by the report of the Spanish National Board for markets and competition (CNMC [89]) regarding Spanish airports being able to compete if the management is transferred individually to the airports rather than being centralised. Again, the centralization of the management ends with excess in infrastructures not required and therefore becoming an inefficient system with low flexibility for the airports to decide essential commercial policies not-sustainable in the medium-long term.

In conclusion, the Spanish Airport-System becomes a system with many small airports (and potentially medium airports) not needed to attend public needs. The Spanish Airport-System punishes big airports (with more than $3,500,000$ passengers per year) for achieving positive gross margins since these represent a transfer of financial recourse to no profitable airports and therefore, the Spanish Airport-System does not incentive airports to become economic efficient (profitable). Centralized decisions regarding investments in infrastructure to be made in airports that are not required for the actual demand along with wrong forecasted budgets, end in a loss of public funding that could be applied to other requirements and also highlights the need of critically assess the effectiveness of the Spanish Government's decision and management processes. Aggressive depreciation policies along with excessive air fares that do not correspond to the matching and accruals accounting conventions of individual airports enhance the discussion regarding the fairness and truthfulness of the financial reports and financial statements. Medium and small airports become overall an excess of idle resources for the Spanish Airport-System since these airports are not able to generate enough income to cover their operational and fixed costs. Different alternatives of travelling within the catchment areas (such as motorways and railways) along with a standardized-centralised decision process which eradicates any sign of competition, do not allow the Spanish Airport-System to recover. The Spanish Government (AENA) should consider thoughtfully the win-win results by deciding closing most of these airports avoiding transferring financial resources from larger airports to others (no profitable airports), in order not only to increase the actual results of the biggest airports, but their technical efficiency levels as well as to reduce the public deficit.

\section{Further Research}

Future research will include a second stage methodology. The efficiency scores will be used as dependent variables to determine if environmental variables can explain the efficiency levels of the Spanish airports owned and managed by AENA. This second stage is essential to find out the main reasons behind why some airports are efficient and others are not, therefore to explain the efficiency map obtained in the earlier stage, to achieve reliable explanations to consolidate the main causes of the efficiency frontier obtained previously (61). The revision of literature proves that authors differ in their conclusions when using only one stage instead of applying a second methodology. 26

In the second stage of this study environmental variables will be considered. Environmental variables are defined as not-controllable since they cannot be change depending on managerial decisions. In literature they are named as non-discretionary variables since are assumed to be beyond the control of management in the short run or they are exogenously restricted (9) Non-discretionary variables can be understood as the environment where airports develop their aeronautical activity. The most common environmental variable in the airport sector is the type of management and ownership especially when the regulator is the government. The environmental variables to be considered are related to demographic characteristics of airports (GDP per capita and population of the city; number of airports within the catchment area; weather conditions; etc.); type of airports (coordinate; slots; heliports; hubs; etc.) as well as the type of air traffic control they are restricted to (ATZ; CTR; CTA; TMA, etc.). Also, the type of returns to scale will be disclosure between constant (CCR model) and variable (BCC model) with the aim of separating the total efficiency score into pure technical efficiency and scale efficiency. The pure technical efficiency level will show how airports develop their activity with the current resources feasible. The efficiency scale will determinate if airports are using their whole capacity, therefore if the size is adequate to produce the airport activity or they are under-using their current resources. One must take into consideration the importance of this efficiency as these results could become biased by the existence of larger and smaller airports in the sample.

Finally the n-year-window DEA method (adjusted DEA) will be used to construct a smoothly frontier avoiding instable efficiency scores across years and therefore, obtaining an accurate frontier to be used in the second stage methodology.

Structural changes in the airport industry lead the interest on benchmarking.

\section{REFERENCES}

[1] Adler, N. \& Golany B. (2002): 'Including Principal

26 Parker (1999) found that British Airports Authority (BAA) privatization had not impact in airport technical efficiency whereas Yokomi (2005) using Malmquist Index which provides dinamism found that almost all airports managed by BAA have improved their technical efficiency after privatization. 
Component weights to improve discrimination in Data Envelopment Analysis'. Journal of the Operational Research Society 53, 1-7

[2] Adler, N. \& Yazhemsky, E. (2010): 'Improving discrimination in Data Envelopment Analysis: PCA-DEA or variable reduction'. European Journal of Operational Research 202, 273-284

[3] Adler, N. \& Yazhemsky, E. (2006): 'A Guide to PCA-DEA Version 1: Principal Component Analysis \& Data Envelopment Analysis'. Internal Publication, School of Business Administration. Hebrew University of Jerusalem.

[4] Adler, N.; Liebert, V. \& Yazhemsky, E. (2013): 'Benchmarking airports from a managerial perspective' Omega 41, 442-458

[5] Asmild, M. \& Pastor, J.T. (2010): 'Slack free MEA and RDM with comprehensive efficiency measures'. Omega 38, 475-483

[6] Assaf, A. (2009): 'Accounting for size in efficiency comparisons of airports' Journal of Air Transport Management 15, 256-258

[7] Advani, A. (1999): "Passenger friendly airports: another reason for airport privatisation" The Reason Public Policy Institute. L.A. Policy Study 254

[8] Backx, M.; Carney, M. \& Gedajlovic, E. (2002): "Public, private and mixed ownership and the performance of international airlines" Journal of Air Transport Management $8,213-220$

[9] Banker, R. D. \& Morey, R. C. (1986): 'Efficiency analysis for exogenously fixed inputs and outputs' Operations Research 34, 513-521

[10] Barros, C. P. \& Dieke, P.U.C. (2008): 'Measuring the economic efficiency of airports: A Simar-Wilson methodology analysis' Transportation Research Part E 44, 1039-1051

[11] Barros, C. P. \& Sampaio, A. (2004): 'Technical and allocative efficiency in airports' International Journal of Transport Economics 31, 355-377

[12] Bazargan, M. \& Vasigh, B. (2003): "Size versus efficiency: a case study of US commercial airports" Journal of Air Transport Management 9, 187-193

[13] Banker, R. D. \& Morey, R. C. (1986): 'Efficiency analysis for exogenously fixed inputs and outputs'. Operations Research 34, 513-521

[14] Bishop, M. \& Kay, J. (1989): 'Privatization in the United Kingdom: Lessons from Experience'. World Development Vol. 17 (5), 643-657

[15] Brockett, P.L.; Rousseau, J. J.; Wang, Y. \& Zhow, L. (1997): 'Implementation of DEA Models using GAMS'. University of Texas, Austing. Research Report 765

[16] Bush, H. \& Storey, D. (2013): 'The economics and regulation of on-board carriage of European airport retail sales. A policy research study for the European Travel Retail Confederation'

[17] Camp, R. (1989): 'Benchmarking: the search for best practices that lead to superior performance'. Quality Progress 22(1), 61-68
[18] Carney, M. \& Mew, K. (2003): 'Airport governance reform: a strategic management perspective'. Air Transport Management 9, 221-232

[19] Charkham, J. P. (1994): 'Keeping good company: a study of corporate governance in five countries'. Oxford University Press, New York

[20] Charnes, A.; Cooper, W. W.; Rhodes, E. (1978): 'Measuring the efficiency of decision making units'. European Journal of Operational Research 2, 429-444

[21] Charnes, A.; Cooper, W. W.; Golany, B.; Seiford, L. \& Stutz, J. (1985): 'Foundations of data envelopment analysis for Pareto-Koopmans efficient empirical production functions'. Journal of Econometrics 30, 91-107

[22] Coelli, T.J.; Rao, D.S.P.; O’Donnell, C.J. \& Battese, G.E. (2005): 'An Introduction to Efficiency and Productivity Analysis'. Springer, New York.

[23] Cooper, W. W.; Seiford, L. M. \& Thrall, R. M. \& Zhu, J. (2001): 'Sensitivity and stability analysis in DEA: some recent developments'. Journal of Productivity Analysis 15, 217-246

[24] Cooper, W. W.; Kyung, S.P. \& Pastor, J. T. (1999): 'RAM: a range adjusted measure of inefficiency for use with additive models, and relations to other models and measures in DEA'. Journal of Productivity Analysis 11, 5-42

[25] Costas-Centivany, C.M. (1999): "Spain's airport infrastructure: adaptations to liberalization and privatisation" Journal of Transport Geography 7, 215-223

[26] De Alessi, L. (1980): "The economics of property rights: a review of the evidence" Research in Law and Economics. JAI Press (Greenwich)

[27] De Alessi, L. (1983): "Property rights transaction costs and X-efficiency: an essay in economic theory" American Economic Review 73, 64-81

[28] Debreu, G. (1951): 'The coefficient of resource utilization'. Econometrica 19, 273-292

[29] Fare, R. \& Grosskopf, S. (2000): 'Theory and application of directional distance functions'. Journal of Productivity Analysis 13(2), 93-103

[30] Farrell, M. J. (1957): 'The measurement of productive efficiency'. Journal of the Royal Statistical Society (A) 120, 253-290

[31] Francis, G.; Humphreys, I. \& Fry, J. (2002): "The benchmarking of airport performance" Air Transport Management 8, 239-247

[32] Freathy, P. (2004): "The commercialisation of European airports: successful strategies in a decade of turbulence " Air Transport Management 10, 191-197

[33] Freathy, P. \& O' Connell, F. (1998): European Airport Retailing. Macmillan, Basingstoke.

[34] Galve, C. \& Salas, V. (1996): “Ownership Structure and Firm Performance: Some Empirical Evidence from Spain” Managerial and Decision Economics 17, 575-586

[35] Gerber, P. (2002): "Success factors for the privatisation of airports-an airline perspective" Air Transport Management 8, 29-36 
[36] Graham, A.; Papatheodorou, A. \& Forsyth, P. (2010): 'Aviation and Tourism. Implications for Leisure Travel'. Ashgate, Surrey.

[37] Gorin, T. \& Belobaba, P. (2004): "Impacts of entry in airline markets: effects of revenue management on traditional measures of airline performance" Air Transport Management 10, 259-270

[38] Gormley, W. T. (1991): "Privatization and Its Alternatives" The University of Wisconsin Press, Madison (Wisconsin)

[39] Guillaume, B. \& Hakfoort, J. (2001): "The evolution of the European aviation network, 1990-1998" Air Transport Management 7, 311-318

[40] Gillen, D. (2009): "The evolution of the Airport Business: Governance, Regulation and Two-Sided Platforms" Paper presented in Hamburg Aviation Conference, Hamburg (February 2009)

[41] Gillen, D. \& Lall, A. (1997): "Developing measures of airport productivity and performance: an application of data envelopment analysis" Transportation Research-E 33, Issue $4,261-273$

[42] Halpern, N. \& Brathen, S. (2011): 'Impact of airports on regional accessibility and social development' Journal of Transport Geography 19, 1145-1154

[43] Henser, D.A. \& Waters, W.G. (1993): "Using Total Factor Productivity and Data Envelopment Analysis for performance comparisons among government enterprises: concepts and issues" Institute of Transportation Studies, University of Sidney (Sidney)

[44] Holloway, J.A.; Hinton, C. M. \& Francis, G.A. (1999): "Identifying best practice in benchmarking" CIMA Research Monograph, London.

[45] Hooper, P (2002): 'Privatisation of airports in Asia'. Journal of Air Transport Management 8, 289-300

[46] Hooper, P.; Cain, R. \& White, S. (2000): 'The privatisation of Australia's airports'. Transportation Research Part E 36, $181-204$

[47] Humphreys, I. (1999): "Privatisation and commercialisation Changes in UK airport ownerships patterns" Journal of Transport Geography 7, 121-134

[48] Jenkins, D. (1999): "Small changes make big differences: the need for improved air traffic control and aviation infrastructure" George Washington University.

[49] Jensen, M. \& Meckling, W. (1979): "Rights and production function: an application to labour-managed firms and co-determination" Journal of Financial Economics 3, 305-506

[50] Koopmans, T.C. (1951): 'Activity analysis of production and allocation'. Willey, New York.

[51] Levy, N. (1987): "A theory of public enterprise behaviour" Journal of Economic Behaviour and Organization 8, 75-96

[52] Lin, L.C. \& Hong, C.H. (2006): "Operational performance evaluation of international major airports: An application of data envelopment analysis" Journal of Air Transport Management 12, 342-351

[53] Lovell, C. A. K. \& Pastor, J.T. (1995): 'Units invariant and translation invariant DEA models' Operational Research Letters 18, 147-151

[54] Martín, J.C. \& Román, C. (2001): “An Application of DEA to Measure the Efficiency Spanish Airports Prior to Privatization" Journal of Air Transport Management 7, Issue $3,149-157$

[55] Massaud, B. \& Vasigh, B. (2003): "Size versus efficiency: a case study of US commercial airports" Journal of Air Transport Management 9, 187-193

[56] Mew, K. (2000): “The Privatization of Commercial Airports in the United States. What is wrong with the Federal Aviation Administration Privatization Program, and what might be more successful?" Public Works Management \& Policy 5(2), 99-105

[57] Murillo-Melchor, C. (1999): 'An Analysis of Technical, Efficiency and Productivity Changes in Spanish Airports by using the Malmquist Index' Departamento de Economía. Universidad de Cantabria.

[58] Nyshadham, E.A. \& Rao, V.K. (2000): “Assessing Efficiency of European Airports. A Total Factor Productivity Aproach" Public Works Management and Policy 5(2), 106-114

[59] Oum, T. H.; Yu, C. \& Fu, X. (2003): 'A comparative analysis of productivity performance of the world's major airports: summary report of the ATRS global airport benchmarking research report 2002' Journal of Air Transport Management 9, 285-297

[60] Oum, T. H. \& Yu, C. (2004): 'Measuring airports' operating efficiency: a summary of the 2003 ATRS global airport benchmarking report' Transportation Research Part E: Logistics and Transportation Review 40, 515-546

[61] Oum, T. H.; Adler, N. \& Yu, C. (2006): Privatization, corporatization, ownership forms and their effects on the performance of the world's major airports Air Transport Management 12, 109-201

[62] Oum, T. H.; Adler, N.; Yan, J. \& Yu, C. (2008): 'Ownership forms matter for airport efficiency: A stochastic frontier investigation of worldwide airports' Journal of Urban Economics 64, 422-435

[63] Parker, D. (1999): 'The performance of BAA before and after privatisation'. Journal of Transport Economics and Policy 33, 133-145

[64] Pels, E.; Nijkamp, P. \& Rietveld, P. (2001): 'Relative efficiency of European airports' Transport Policy 8, 183-192

[65] Pels, E.; Nijkamp, P. \& Rietveld, P. (2003): 'Inefficiencies and scale economies of European airport operations' Transport Research Part E 39, 341-361

[66] Pestana B.C. (2008): 'Airports in Argentina: Technical efficiency in the context of an economic crisis' Journal of Air Transport Management 14, 315-319

[67] Pestana, B. C. \& Dieke, P. (2007): 'Performance evaluation of Italian airports: A data envelopment analysis' Journal Air Transport Management 13, 184-191

[68] Pestana, B. C. \& Dieke, P. (2008): 'Measuring the economic efficiency of airports: A Simar-Wilson methodology analysis' Transport Research-E, 44, 1039-1051 
[69] Pestana, B. C. \& Sampaio, A. (2004): 'Technical and allocative efficency in airports' International Journal of Transport Economics 31, 355-377

[70] Pope, K. (1996): 'Airport privatisation begins to take off, led by Britain's BAA' The Wall Street Journal 14, A1-A8

[71] Porter, M.E. (March/April 1979). 'How Competitive Forces Shape Strategy'. Harvard Business Review

[72] Rendeiro, R. (2002): 'An approximation to the productive efficiency of the Spanish airports network through a deterministic cost frontier' Air Transport Management 8, 233-238

[73] Russell, R. R. (1985): 'Measures of technical efficiency'. Journal of Economic Theory 35, 109-126

[74] Sarkis, J. (2000): 'An analysis of the operational efficiency of major airports in the United States' Journal of Operations Management 18, 335-351

[75] Starkie, D. (2002): 'Airport regulation and competition' Journal of Air Transport Management 8, 63-72

[76] Simar, L. \& Wilson, P.W. (1999; 2007): 'Estimation and inference in two stage, semi-parametric models of productive efficiency' Journal of Econometrics 136, 31-64

[77] Simar, L. \& Wilson, P.W. (1999): 'Of course we can bootstrap DEA scores! But does it mean anything? Logic trumps wishful thinking.' Journal of Productivity Analysis 11, 93-97

[78] Tapiador, F. J.; Mateos, A. \& Martí-Henneberg, J. (2008): 'The geographical efficiency of Spain's regional airports: A quantitative analysis' Journal of Air Transport Management $14,205-212$

[79] Tone, K. (2001): 'A slack-based measure of efficiency in data envelopment analysis.' European Journal of Operational Research 130, 498-509

[80] Tovar, B. \& Martin-Cejas, R.R. (2009): 'Are outsourcing and non-aeronautical revenues important drivers in the efficiency of Spanish airports?.' Journal of Air Transport Management 15, 217-220

[81] Truitt, L.J. \& Esler, M. (1996): 'Airport privatization: full divestiture and its alternatives'. Policy Studies Journal 24, $100-110$
[82] Wanke, P. (2012): 'Efficiency of Brazil's airports: Evidences from bootstrapped DEA and FDH estimates'. Journal of Air Transport Management 23, 47-53

[83] White, P. (1994): "Public transport: privatisation and investment" Transport Policy 1 (3), 184-194

[84] Williams, G. \& Pagliari, R. (2004): 'A comparative analysis of the application and use of public service obligations in air transport within the EU' Transport Policy 11, 55-66

[85] Yokomi, M. (2005): 'Evaluation of technical efficiency at privatised airports: case of BAA Plc.' In a paper presented at the Air Transport Research Society (ATRS) Conference, $3^{\text {rd }}-6^{\text {th }}$ July 2005 Rio de Janeiro (Brasil)

[86] Yoshida, Y. \& Fujimoto, H. (2004): 'Japanese-airport benchmarking with the DEA and endogenous-weight TFP methods: testing the criticism of over investment in Japanese regional airports' Transportation Research Part E: Logistics and Transportation Review 40, 533-546

\section{Reports}

[87] Abertis (2009): 'Ten years that marked an historic era change in the presidency'. Issue 17

[88] Cambra de Comerç de Barcelona (November 2010): 'El modelo de gestión aeroportuaria en España: marco institucional y jurídico y líneas maestras para una propuesta de cambio'

[89] Comisión Nacional de los Mercados y la Competencia (CNMC, July 2014): 'El Sector Aeorportuario en España: Situación Actual y Recomendaciones de Liberización'

[90] Comité de Regulacion Ferroviaria y Aeroportuaria (CRFA, September 2013): 'Informe de Supervisión sobre la propuesta de modificatión tarifaria de AENA Aeoropuertos, S.A. para 2014'

[91] International Civil Aviation Organization (ICAO) (March 2013): Worldwide Air Transport Conference (ATCONF) Sixth meeting: Airport Competition.

http://www.ine.es/jaxi/tabla.do?type=pcaxis\&path=/t38/p60 4/a2000/10/\&file=07050c1.px

http://www.heathrowairport.com/about-us/investor-centre/do cument-centre/annual-accounts 